\title{
The heterologous expression of a plastocyanin in the diatom Phaeodactylum tricornutum improves cell growth under iron- deficient conditions
}

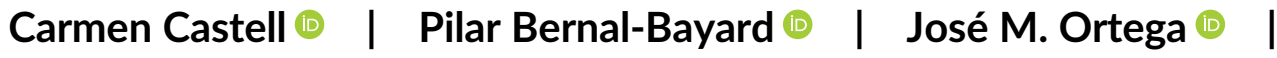 \\ Mercedes Roncel $\odot$ | Manuel Hervás $₫ \quad$ José A. Navarro ${ }^{\circledR}$
}

Instituto de Bioquímica Vegetal y Fotosíntesis, cicCartuja, Universidad de Sevilla and CSIC, Seville, Spain

\section{Correspondence}

José A. Navarro, Instituto de Bioquímica

Vegetal y Fotosíntesis, cicCartuja, Universidad de Sevilla and CSIC, Seville, Spain.

Email: jnavarro@ibvf.csic.es

Funding information

Junta de Andalucía, Grant/Award Number: PAIDI BIO-022; Ministerio de Economía, Industria y Competitividad, Gobierno de España, Grant/Award Number: BIO2015-64169-P

Edited by: A. Krieger-Liszkay

\begin{abstract}
We have investigated if the heterologous expression of a functional green alga plastocyanin in the diatom Phaeodactylum tricornutum can improve photosynthetic activity and cell growth. Previous in vitro assays showed that a single-mutant of the plastocyanin from the green algae Chlamydomonas reinhardtii is effective in reducing P. tricornutum photosystem I. In this study, in vivo assays with P. tricornutum strains expressing this plastocyanin indicate that even the relatively low intracellular concentrations of holo-plastocyanin detected $(\approx 4 \mu \mathrm{M})$ are enough to promote an increased growth (up to 60\%) under iron-deficient conditions as compared with the WT strain, measured as higher cell densities, content in pigments and active photosystem I, global photosynthetic rates per cell, and even cell volume. In addition, the presence of plastocyanin as an additional photosynthetic electron carrier seems to decrease the over-reduction of the plastoquinone pool. Consequently, it promotes an improvement in the maximum quantum yield of both photosystem II and I, together with a decrease in the acceptor side photoinhibition of photosystem II-also associated to a reduced oxidative stress-a decrease in the peroxidation of membrane lipids in the choroplast, and a lower degree of limitation on the donor side of photosystem I. Thus the heterologous plastocyanin appears to act as a functional electron carrier, alternative to the native cytochrome $c_{6}$, under iron-limiting conditions.
\end{abstract}

\section{I INTRODUCTION}

Photosynthetic productivity, which is equally shared between terrestrial and oceanic systems, is due to a wide variety of organisms, from cyanobacteria to eukaryotic microalgae and plants (Field et al., 1998; Hall, 1976). Within the group of eukaryotic microalgae, diatoms constitute the dominant life form in oceanic phytoplankton, probably

Abbreviations: $\mathrm{Cb}_{6} \mathrm{f}$, cytochrome $b_{6} f ; \mathrm{Cc}_{550}$, cytochrome $\mathrm{c}_{550}$; $\mathrm{Cc}_{6}$, cytochrome $c_{6} ; \mathrm{Cf}$, cytochrome f; Chl, chlorophyll; ET, electron transfer; Fd, ferredoxin; Fld, flavodoxin; HTL, high temperature thermoluminescence; $\mathrm{P}_{700}$, photosystem I primary donor; $\mathrm{Pc}$, plastocyanin; $\mathrm{PQ}$, plastoquinone; PSI, photosystem I; PSII, photosystem II; STL, standard thermoluminescence; $t_{1 / 2}$, half-life time; TL, thermoluminescence; $t_{\max }$, temperature of the maximum of a $\mathrm{TL}$ band. representing the largest group of biomass producers on earth (Bowler et al., 2010).

The oxygenic photosynthetic electron transfer (ET) chain is composed of three large multisubunit membrane-embedded complexes: photosystem II (PSII), cytochrome $b_{6} f\left(\mathrm{Cb}_{6} \mathrm{f}\right)$, and photosystem I (PSI), all of which contain iron cofactors and are connected by mobile electron carriers (Blankenship, 2014). In terrestrial plants, electrons from the $\mathrm{Cb}_{6} \mathrm{f}$ complex are transferred to PSI inside the thylakoidal lumen by plastocyanin (Pc), a small (ca. 100 amino acids) soluble Type-1 blue copper-protein. In contrast, electrons exiting PSI are delivered to ferredoxin ( $\mathrm{Fd})$, an iron-sulfur protein. However, in aquatic systems many photosynthetic microorganisms maintain alternative electron transporters couples (Hervás et al., 2003). Thus, in most cyanobacteria 
and unicellular green algae, Pc is produced when copper is available, but under low-copper conditions $P c$ is replaced by cytochrome $c_{6}$ $\left(\mathrm{Cc}_{6}\right)$, a typical Class I c-type cytochrome (ca. 90 amino acids). In turn, the flavoprotein flavodoxin (Fld) replaces Fd under iron-limiting conditions (De la Rosa et al., 2006; Hervás et al., 2003; Sancho, 2006; Sétif, 2006). The functional and structural equivalence of both couples, $\mathrm{Pc} / \mathrm{Cc}_{6}$ and $\mathrm{Fd} / \mathrm{Fld}$, is well established (Bendall \& Howe, 2016; Hervás et al., 1995, 2003; Hippler \& Drepper, 2006).

The existence of redox alternative couples in photosynthesis can be understood as an adaptation to fluctuations in the bioavailability of iron in the aquatic environments. Many studies have revealed that iron limitation is the major factor controlling the primary productivity and growth of phytoplankton in vast oceanic areas (Boyd et al., 2007; Moore \& Braucher, 2008). Massive oceanic iron fertilization experiments have also shown the appearance of algal blooms, in many cases dominated by diatoms, suggesting that these eukaryotic algae, in particular, are very sensitive to iron limitations (Morrissey \& Bowler, 2012). Among other effects, iron starvation causes a severe decrease in the chlorophyll content and drastic alterations in the photosynthetic efficiency in diatoms, promoting a decrease in the content of both the iron-rich PSI and $\mathrm{Cb}_{6} \mathrm{f}$ complexes and resulting in an increased PSII:PSI ratio (Allen et al., 2008; Lommer et al., 2012; Marchetti et al., 2012).

However, the occurrence of alternative couples is only partially maintained in the red lineage of photosynthetic organisms that diverged along evolution from the green lineage and that comprises, among others, red algae, cryptophytes, stramenopiles (that include diatoms), and haptophytes (Falkowski et al., 2004). Thus, whereas Fld is widely produced in the red lineage as an alternative to Fd under low iron conditions (Pierella Karlusich et al., 2014), $\mathrm{Cc}_{6}$ is the only electron carrier from cytochrome $f(\mathrm{Cf})$-in the $\mathrm{Cb}_{6} \mathrm{f}$ complex-to PSI in red algae and in the majority of organisms belonging to the red-plastid lineage, including diatoms, as confirmed by protein characterization, genome sequencing and transcriptomic analyzes (Akazaki et al., 2009; Bernal-Bayard et al., 2013; Blaby-Haas \& Merchant, 2012; Bowler et al., 2010; Groussman et al., 2015). The absence of Pc as an alternative to $\mathrm{C}_{6}$ can thus represent an extra requirement of iron that affects the adaption of these organisms to iron limitations, as $\mathrm{Cc}_{6}$ replacement has been suggested to reduce iron requirements by up to $10 \%$ in open-ocean waters (Boyd et al., 2007; Guo et al., 2010). However, although petJ genes encoding $\mathrm{C}_{6}$ have been found in all the sequenced stramenopiles genomes, petE genes encoding Pc, closely related to those from green algae, have been also found in the genomes of several strains of oceanic diatom species. These include Thalassiosira oceanica and Fragilariopsis cylindrus, but also the haptophyte Emiliania huxleyi and the dinoflagellate Karenia brevis (Blaby-Haas \& Merchant, 2012; Nosenko et al., 2006; Peers \& Price, 2006). In addition, analyzes of microbial eukaryotic transcriptomes have detected transcripts encoding for putative Pcs in at least one species from each of the major diatom classes (Groussman et al., 2015). All of this has been attributed to the acquisition of petE Pc genes from green alga by horizontal gene transfer, as an adaptation to iron limitation (Groussman et al., 2015; Hippmann et al., 2017;
Marchetti et al., 2012; Peers \& Price, 2006). A particular strain of the open ocean diatom $T$. oceanica has been even described to express constitutively $\mathrm{Pc}$ as the main electron carrier from Cf to PSI, as the two $\mathrm{CC}_{6}$ genes of its genome are weakly expressed (Kong \& Price, 2020; Lommer et al., 2012; Peers \& Price, 2006). The presence of $\mathrm{Pc}$ in diatoms raises, however, some open questions, such as the mechanism regulating either its expression or a putative $\mathrm{C}_{6} / \mathrm{Pc}$ alternation in function of the copper/iron levels (Hippmann et al., 2017; Lommer et al., 2012; Marchetti et al., 2012; Roncel et al., 2016). In addition, the existence of a still not found specific transporting system carrying copper into the lumen, to be incorporated into the $\mathrm{Pc}$, is another unresolved question (Guo et al., 2010, 2015; Kong \& Price, 2019; Levy et al., 2008).

Clear evidence for the production of a functional Pc protein has been only presented in the case of $T$. oceanica, where relatively small amounts per cell of the holoprotein were detected, purified and partially sequenced (Kong \& Price, 2020; Peers \& Price, 2006). However, there is a discordance between the theoretical molecular mass of the T. oceanica mature $\mathrm{Pc}(10,300 \mathrm{Da})$ and the apparent experimental mass found for the purified protein (18,200 Da) (Peers \& Price, 2006). In any case, the Pc-translated sequence in diatoms is closely related to that from green algae, and thus the "red-type"-acquired Pc would show the features of a "green-type" Pc. In green algae (and plants) Pc, two well-defined functional areas can be described: (1) a hydrophobic ET area, determined by the accessibility to the solvent of the redox cofactor and (2) a strong negatively charged area for the interaction with complementary positive patches in Cf and PSI. Similar functional areas have been proved to be also present in green $\mathrm{Cc}_{6}$ (De la Rosa et al., 2006; Guss \& Freeman, 1983; Hippler \& Drepper, 2006; Ubbink et al., 1998). However, whereas $\mathrm{C}_{6}$ from red algae and diatoms still preserves the hydrophobic ET area, it shows a significant decrease in the negative character of the electrostatic area (Akazaki et al., 2009; Bernal-Bayard et al., 2013; Yamada et al., 2000), parallel with equivalent changes in the electrostatics features of PSI (Antoshvili et al., 2019; Bernal-Bayard et al., 2013, 2015) and Cf (unpublished data). Consequently, in vitro kinetic analyzes of the interaction of diatom PSI with green algae and plants Pcs, suggest that if an alternative $\mathrm{Pc}$ in diatoms could represent a favorable adaptation to iron limitation, its "green-type" character may, however, limit its ET efficiency. Remarkably, this efficiency increased in some green alga Pc mutants replacing negative charges for positive ones to approximate the electrostatics of diatom $\mathrm{Cc}_{6}$ (Bernal-Bayard et al., 2015).

We have here investigated if the heterologous expression in the pennate model diatom Phaeodactylum tricornutum of a functional green alga $\mathrm{Pc}$ under iron-limiting conditions-as an alternative to $\mathrm{CC}_{6}-$ can improve photosynthetic activity and cell growth. $P$. tricornutum is sensitive to iron limitation, and both lacks Pc and produces $\mathrm{CC}_{6}$ (Akazaki et al., 2009; Allen et al., 2008; Bernal-Bayard et al., 2013). For this purpose, we have carried out the construction of $P$. tricornutum strains expressing a mutant of the Pc from the green algae Chlamydomonas reinhardtii, that was previously shown to be more effective than the WT Pc in reducing diatom PSI in vitro (BernalBayard et al., 2015). 


\section{2 | MATERIALS AND METHODS}

\section{$2.1 \mid$ Cell cultures}

Cells from the coastal pennate diatom Phaeodactylum tricornutum CCAP 1055/1 were grown in artificial seawater (ASW) medium (Goldman \& McCarthy, 1978; McLachlan, 1964) in a rotatory shaker (50 rpm) at $20^{\circ} \mathrm{C}$ with regular transfer of the cells into fresh media. The cultures were illuminated by led white light (4500 K) lamps giving an intensity of $20 \mu \mathrm{mol} \mathrm{m}{ }^{-2} \mathrm{~s}^{-1}$ (T8-150MWBL led lamps, Wellmax) following a light/dark cycle of $16 / 8 \mathrm{~h}$. For the experiments to study the effects of iron deficiency, cells from 7 days old cultures were pelleted at $5000 \mathrm{~g}$ for $5 \mathrm{~min}$ and suspended and grown in fresh ASW medium under iron-replete $(12 \mu \mathrm{M} \mathrm{Fe})$ or iron-deficient (10 $\mathrm{nM} \mathrm{Fe}$ plus $0.3 \mathrm{mg} \mathrm{L}^{-1}$ of copper) culture conditions, with transfer of the cells into the same fresh media after a week. Then, the cultures were grown for another 15 days. Except when indicated, most of the exper-

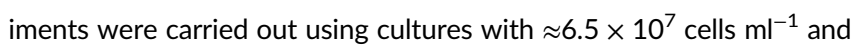
$\approx 2 \times 10^{7}$ cells $\mathrm{ml}^{-1}$, respectively, for iron-replete and iron-deficient conditions.

\section{2 | Plasmids construction}

The nucleotide sequence of the WT Pc from the green alga Chlamydomonas reinhardtii was retrieved from the GenBank-NCBI database. A synthetic Pc petE gene, with the E85K mutation (BernalBayard et al., 2015), was designed with the codon usage of P. tricornutum (https://www.kazusa.or.jp/codon/). Moreover, the Fld promoter (induced in the absence of iron) and the transit peptide of $\mathrm{Cc}_{6}$ (directing the protein to the thylakoid lumen) of $P$. tricornutum were added upstream to the Pc-translated sequence. However, as the native $\mathrm{C}_{6}$ gene of $P$. tricornutum has an intron (280 nucleotides) within the $\mathrm{N}$-terminal plastid targeting sequence (Killian \& Kroth, 2004), two constructions with alternative versions of the transit peptide of $\mathrm{Cc}_{6}$ were designed, with or without the sequence corresponding to the intron (Figure S1). The synthetic plasmids were generated by GeneCust (https://www.genecust.com/en/) by inserting the Pc petE E85K constructions into pBlueScript II SK (+) vector in EcoRV and Pstl sites. Constructions were then subcloned in the $P$. tricornutum transformation vector Isip1::YFP, kindly provided by the group of Prof. Chris Bowler (IBENS, Paris, France) (Kazamia et al., 2018), in the same restriction sites, to obtain the final pFld_PtCc6_PcE85K and pFld_PtVCc6_PcE85K plasmids (with and without the intron, respectively). Both plasmids were checked by sequencing (NZYTech), using the oligonucleotides pPisipF (5'-TCT CGTGTGGTCATGGGTTG- $3^{\prime}$ ) and pPisipR (5'-ACGACTTCTTCAA GTCCGCC- $\left.3^{\prime}\right)$. To obtain antibodies against the Fld from P. tricornutum, the FLDA1 gene coding for Fld was first amplified by PCR from genomic DNA, using the iProof ${ }^{\mathrm{TM}}$ High-Fidelity DNA Polymerase (Bio-Rad) and adequate oligonucleotides. The PCR product was then cloned into the pET-28 b (+) vector (Novagen) to obtain the pET-28 b_Fld plasmid for expressing the His-tagged protein in E. coli.
All plasmids were maintained in the $E$. coli $\mathrm{DH} 5 \alpha$ strain (Hanahan, 1983), isolated when required as described by Ish-Horowicz and Burke (1981) and quantified using a NanoDrop N1000 spectrophotometer.

\section{3 | Cell transformation by biolistic}

P. tricornutum cells were transformed using the Biolistic PDS-1000/ He Particle Delivery System (Bio-Rad) as previously described (Apt et al., 1996; Falciatore et al., 1999). Approximately $5 \times 10^{7}$ cells, harvested at mid-logarithmic phase, were spread on ASW/1\% (w/v) agar plates and incubated for $24 \mathrm{~h}$. M17 tungsten microcarrier particles (1.1 $\mu \mathrm{m}$ diameter; Bio-Rad) were coated with plasmid DNA using $\mathrm{CaCl}_{2}$ and spermidine as indicated by the supplier. Agar plates were located at level two within the chamber and a burst pressure of 1550 psi was used for the bombardment. The cells were cotransformed with the pPha-T1 vector containing zeocin resistance, also kindly provided by the group of Prof. Chris Bowler. As a control of the possible effects of the zeocin resistance, an experiment in which $P$. tricornutum was transformed only with the zeocin resistance vector was also carried out (B1 mutants). Afterward, the plates were incubated for $48 \mathrm{~h}$ in the dark before being spread onto new ASW agar plates containing $100 \mu \mathrm{g} \mathrm{ml}^{-1}$ of zeocin (InvivoGen) to allow the selection of transformants. Plates were then maintained under illumination with a light/dark cycle of $16 / 8 \mathrm{~h}$ at $20^{\circ} \mathrm{C}$ as described above. Individual resistant colonies appearing 3-4 weeks after transformation were restreaked on new ASW agar plates containing zeocine. The presence of the Pc gene in zeocin-resistant colonies was checked by colony PCR, using the oligonucleotides pPisipF and pPisipR and the MyTaq $^{\text {TM }}$ Polymerase (Bioline), according to manufacturer's instructions. The amplified products were visualized through DNA electrophoresis in 0.7\% (w/v) agarose gel (Sambrook \& Russell, 1989).

\subsection{Analytical methods}

Growth cell parameters were obtained from at least 10 independent experiments. Cells were counted with a Neubauer-Improved hemocytometer (Marienfeld-Superior), according to the manufacturer's instructions. Cell specific growth rate $\left(\mu\right.$, day $\left.^{-1}\right)$ was calculated after 15 days of culture growth as: $\left[\mu=\ln \left(N_{t} / N_{0}\right) / \Delta t\right]$ where $N_{t}$ and $N_{0}$ are the final and initial cell concentration, respectively, and $\Delta t$ is the days of growth. Pigments extraction with acetone was carried out basically as described by Kong and Price (2020), but with an initial step of incubation at $70^{\circ} \mathrm{C}$ for $30 \mathrm{~min}$. The total chlorophyll content in P. tricornutum cells was determined according to Arnon (1949). The chlorophyll $a$ and $c$ estimated content was determined as described by Jeffrey and Humphrey (1975), whereas carotenoid concentration was determined by the equation given by Strickland and Parsons (1972):

$$
\operatorname{Chl} a\left(\mu \mathrm{gml}^{-1}\right)=11.47 \times\left(\mathrm{A}_{664}-\mathrm{A}_{750}\right)-0.40 \times\left(\mathrm{A}_{630}-\mathrm{A}_{759}\right)
$$




$$
\begin{gathered}
\operatorname{Chlc}\left(\mu \mathrm{g} \mathrm{ml}^{-1}\right)=24.34 \times\left(\mathrm{A}_{630}-\mathrm{A}_{750}\right)-0.40 \times\left(\mathrm{A}_{664}-\mathrm{A}_{759}\right) \\
\text { Carotenoid }\left(\mu \mathrm{g} \mathrm{ml}^{-1}\right)=7.6 \times\left[\left(\mathrm{A}_{480}-\mathrm{A}_{750}\right)-1.49 \times\left(\mathrm{A}_{510}-\mathrm{A}_{750}\right)\right]
\end{gathered}
$$

For protein determination, $P$. tricornutum cells were pelleted and resuspended in 100-150 $\mu$ l of lysis buffer [ $50 \mathrm{mM}$ Tris- $\mathrm{HCl}, \mathrm{pH} 7.5$, buffer supplemented with $2 \%$ SDS, 10 mM EDTA and a tablet of the protease inhibitor cocktail (cOmplete ${ }^{\mathrm{TM}}$ ULTRA Tablets, EASYpack, Roche)]. The cells were incubated at $37^{\circ} \mathrm{C}$ for $30 \mathrm{~min}$ with occasional vortexing. Soluble protein fractions were obtained by centrifugation at $15000 \mathrm{~g}$ for $30 \mathrm{~min}$ at $4{ }^{\circ} \mathrm{C}$, and the protein concentration was determined according to the Lowry method (Lowry et al., 1951).

The $\mathrm{Cc}_{6}$ and $\mathrm{Pc}$ E85K content in P. tricornutum cells were determined following a modification of the method previously described (Bernal-Bayard et al., 2017). P. tricornutum cells were collected by centrifugation. Wet pellets ( $\approx 3 \mathrm{~g}$ ) were weighed and resuspended in $20 \mathrm{ml}$ of $20 \mathrm{mM}$ Tris buffer, $\mathrm{pH} 7.5$, supplemented with DNase and the proteases inhibitors PMSF, benzamidine and aminocaproic acid. The cells were then broken by three cycles of French press disruption (20,000 psi), followed by debris precipitation with $55 \%$ ammonium sulfate and further precipitation with $100 \%$ ammonium sulfate. $\mathrm{C}_{6}$ and Pc content were determined in the final resuspended pellets by differential absorbance measurements between the fully reduced (sodium ascorbate) and fully oxidized (potassium ferricyanide) states at $552 \mathrm{~nm}\left(\mathrm{C}_{6}\right.$, reduced minus oxidized) or $600 \mathrm{~nm}$ (Pc, oxidized minus reduced), as previously described (Bernal-Bayard et al., 2015; Roncel et al., 2016). To reduce interferences from $\mathrm{C}_{6}$ absorbance in the determination of $\mathrm{Pc}$, the concentration of $\mathrm{Cc}_{6}$ was first determined and an equivalent concentration of purified $\mathrm{C}_{6}$ was used as a baseline to measure Pc concentration more precisely. P. tricornutum Fld purification was carried out by FPLC (IBVF Chromatography Service) using a HisTrap Fast Flow Crude column (GE Healthcare Life Sciences) from the inclusion bodies of $E$. coli BL21 (DE3) cells transformed with pET-28 b_Fld, after IPTG induction in the presence of $10 \mu \mathrm{M}$ FMN. Purification then continued by following, with some modifications, protocols previously described (Purifying Challenging Proteins Handbook from GE Healthcare, and see also Rogl et al., 1998). MALDI-TOF mass spectrometry (IBVF Proteomic Service) was used to confirm the correct molecular weight of the purified protein.

\section{5 | Western-blot analysis}

For the immunodetection of $C$. reinhardtii $\mathrm{Pc}$ and $\mathrm{P}$. tricornutum $\mathrm{Cc}_{6}$, cytochrome $C_{550}\left(C_{550}\right)$ and $\mathrm{Fld}$, polyclonal antibodies raised against those proteins were generated using standard procedures at the Animal Experimentation Facility (University of Seville, Spain), by subcutaneous injection of $1 \mathrm{mg}$ of the purified proteins into a white New Zealand rabbit (Bernal-Bayard et al., 2013, 2015, 2017). Commercial antibodies against D1 and PsbO proteins were obtained from Agrisera (products no. AS05 084A and ASO6 142-33, respectively), whereas antibodies against PsaB were kindly provided by Dr. Anna Lindahl (IBVF, Sevilla, Spain).

Protein extracts $(2.5-30 \mu \mathrm{g})$ were resolved on $15 \%(\mathrm{w} / \mathrm{v})$ polyacrylamide gel electrophoresis, as previously described (Roncel et al., 2016), and transferred to a $0.2 \mu \mathrm{m}$ nitrocellulose membrane included in the Trans-Blot ${ }^{\circledR}$ Turbo $^{\mathrm{TM}}$ RTA Midi Nitrocellulose Transfer Kit through the Trans-Blot ${ }^{\circledR}$ Turbo $^{\mathrm{TM}}$ Transfer System (Bio-Rad), following the manufacturer's instructions. The membrane was incubated overnight with a dilution (1:500 to 1:10000) of the selected primary antibody followed by $1 \mathrm{~h}$ incubation with a 1:10000 dilution of the secondary antibody (Goat Anti-Rabbit lgG [H + L]-HRP Conjugate, from Bio-Rad). Finally, the membrane was treated with the Immobilon Western Chemiluminescent HRP Substrate (Millipore) according to the manufacturer's instructions and visualized with the ChemiDoc ${ }^{\mathrm{TM}}$ Imaging System (Bio-Rad). Ponceau total protein stainings were used as loading controls in the immunoblottings.

\section{6 | Microscopy}

To monitor the Pc expression and localization in P. tricornutum transformed strains as well as cell morphology of the different strains, cells were observed and photographed using a Leica Microscope DM6000 B apparatus (IBVF Microscopy Service). The immunostaining and fluorescence microscopy were carried out following the protocol previously described in Szabo and Colman (2007), with some modifications. Cells were extended in a slide and fixed, incubated with rabbit polyclonal anti-Pc antibody, washed, incubated with anti-rabbit FITC secondary antibody (Sigma), washed again and mounted.

The morphology of WT and transformed cells of $P$. tricornutum, grown under iron-replete or iron-deficient conditions, was imaged in vivo also by fluorescence microscopy. Cell volumes and surfaces were calculated from images measurements of longitudinal and transversal cell dimensions from at least 30 cells, and treating P. tricornutum as a two cones model (Levy et al., 2008). In addition, the cell aspect ratio ([Major Axis]/[Minor Axis]) and circularity $\left(4 \pi \times\left(\left[\right.\right.\right.$ Area] $\left.\left./[\text { Perimeter }]^{2}\right)\right)$ shape descriptors were measured by ImageJ Fiji (v. 1.46; Schindelin et al., 2012).

\section{7 | Thermoluminescence analyzes}

Thermoluminescence (TL) glow curves of $P$. tricornutum cell suspensions were obtained using a home-built apparatus designed by Dr. Jean-Marc Ducruet for luminescence detection from 1 to $80^{\circ} \mathrm{C}$ (standard thermoluminescence, STL) and from 10 to $160^{\circ} \mathrm{C}$ (high temperature thermoluminescence, $\mathrm{HTL}$ ). A detailed description of the system can be obtained elsewhere (García-Calderón et al., 2019; Roncel et al., 2016). Temperature regulation, signal recording, and flash sequences were driven by a computer through a National Instrument DAQ-Pad1200 interface, using a specific acquisition program developed by Dr. Ducruet. An electrically insulated resistor heater (Thermocoax), powered by a variable ( 0 to $5 \mathrm{~A}$ ) computer-driven power supply, was mounted below the chamber for temperature regulation. STL and HTL measurements were carried out as described in Roncel 
et al. (2016). TL experiments were carried out in parallel cultures for each strain under iron-replete and iron-deficient conditions. TL parameters were obtained from three independent measurements. Most of the experiments were performed using cultures with a cellular concentration of $\approx 1.5 \times 10^{8}$ and $\approx 5 \times 10^{7}$ cells $\mathrm{ml}^{-1}$ for STL and HTL, respectively.

\section{8 | Photosynthetic measurements}

To study photosynthetic global activity, cells from $2.5 \mathrm{ml}$ of the different cultures were collected by centrifugation and resuspended in fresh culture medium. Oxygen intake or evolution rates were then determined from three independent experiments by using a Clarktype oxygen electrode (Hansatech). Measurements were carried out at $20^{\circ} \mathrm{C}$, both in the dark and under illumination $\left(176 \mu \mathrm{mol} \mathrm{m}^{-2} \mathrm{~s}^{-1}\right)$, to establish the net photosynthetic activity per cell.

The chlorophyll $a$ fluorescence of PSII and the redox state of $\mathrm{P}_{700}$ from intact cells were determined at room temperature using a pulseamplitude modulation fluorometer (DUAL-PAM-100, Walz). The photosynthetic parameters were obtained from five independent experiments, carried out basically as described in Roncel et al. (2016). Prior to measurements, cell suspensions with a cellular concentration of $1.1 \times 10^{8}$ cells $\mathrm{ml}^{-1}$ were dark-adapted for $30 \mathrm{~min}$. The maximum quantum yield of PSII $\left(F_{\mathrm{v}} / F_{\mathrm{m}}\right)$, the relative linear electron transport rates (rETR) and the effective PSII quantum yield $[Y(I I)]$ for each actinic light intensity were determined as previously described (Roncel et al., 2016).

The redox state of $\mathrm{P}_{700}$ was monitored by following the changes in absorbance at $830 \mathrm{~nm}$ versus $875 \mathrm{~nm}$ in cells dark-adapted for $30 \mathrm{~min}$ prior to measurements. Most of the experiments were carried out using cultures with a cellular concentration of $\approx 5.5 \times 10^{7}$ and $\approx 4.5 \times 10^{8}$ cells $\mathrm{mL}^{-1}$ for iron-replete and iron-deficient cultures, respectively. The level of maximal $\mathrm{P}_{700}{ }^{+}$signal observed upon $\mathrm{P}_{700}$ full oxidation, $P_{\mathrm{m}}$, was determined by pre-illumination of cell suspensions with FR light $(730 \mathrm{~nm})$ for $10 \mathrm{~s}$ and after that with a saturating pulse of red light $(635 \mathrm{~nm})$ at $10000 \mu \mathrm{mol} \mathrm{m}{ }^{-2} \mathrm{~s}^{-1}$ intensity and $0.2 \mathrm{~s}$ duration. Following $P_{\mathrm{m}}$ determinations, $\mathrm{P}_{700}{ }^{+}$reduction kinetic decays were recorded in darkness. The average of at least three individual traces from different cultures was taken. The half-life time $\left(t_{1 / 2}\right)$ of the $\mathrm{P}_{700}{ }^{+}$absorption decay was determined by fitting the decays to a single exponential function. The quantum yields of PSI photochemistry, $Y(I)$, donor side limitations, $Y(N D)$, and acceptor side limitations, $Y(N A)$ were determined as described in Roncel et al. (2016).

\section{3 | RESULTS}

\subsection{The E85K mutant Pc of C. reinhardtii can be heterologously expressed in the chloroplast of P. tricornutum}

The expression of Pc in some oceanic species of diatoms has been proposed to constitute an alternative replacement of $\mathrm{CC}_{6}$, similar to what occurs in cyanobacteria and green algae (Groussman et al., 2015; Hippmann et al., 2017; Lommer et al., 2012; Marchetti et al., 2012; Moore \& Braucher, 2008; Peers \& Price, 2006). However, there are no available data about the in vivo functional effects of expressing $\mathrm{Pc}$ in the thylakoidal lumen of diatoms under iron-limiting conditions. Thus, here we investigated the effects of the heterologous expression of a $\mathrm{Pc}$ in $\mathrm{P}$. tricornutum, a diatom that naturally only produces $\mathrm{Cc}_{6}$. We have selected the E85K mutant of the Pc from the green alga $C$. reinhardtii to be expressed in $P$. tricornutum, as this mutant has previously shown to be the most effective $P c$ in reducing diatom PSI in vitro (Bernal-Bayard et al., 2015). The C. reinhardtii E85K Pc gene was placed under the control of the Fld promoter to ensure its expression in low iron conditions (Figure $1 \mathrm{~A}$ ), in which the levels of native $\mathrm{C}_{6}$ drastically decrease and become limiting for the photosynthetic activity (Roncel et al., 2016, and see below). The tripartite transit peptide of the native $\mathrm{Cc}_{6}$ was added to the $\mathrm{Pc}$ gene sequence to warrant the transit of the protein to the thylakoid lumen (Killian \& Kroth, 2004). As the native $\mathrm{Cc}_{6}$ gene of $P$. tricornutum has an intron (280 nucleotides) located within the region coding for the $\mathrm{N}$ terminal plastid targeting sequence (Killian \& Kroth, 2004), a version of the transit peptide of $\mathrm{C}_{6}$ without the sequence corresponding to the intron was also alternatively used (Figure S1).

The presence of the Pc gene in zeocin-resistant transformed colonies was checked by colony PCR and DNA electrophoresis in agarose gels (not shown). The nuclear transformation of $P$. tricornutum is random, which can result in a great variability in the expression of a protein in different clones. Consequently, several $P$. tricornutum strains with different levels of Pc expression were selected (clones \#30, \#45
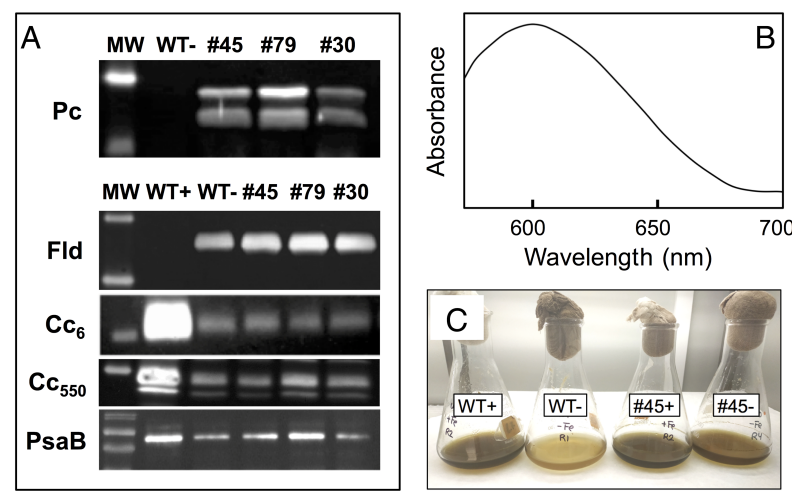

FIGURE 1 (A) Western blot analysis of different photosynthetic proteins in samples from $P$. tricornutum WT and \#30, \#45, and \#79 mutant cells under iron-deficient conditions. MW, molecular weight standard; WT+ and WT-, control WT cells under iron-replete or irondeficient conditions, respectively; $\mathrm{Cc}_{6}$, soluble cytochrome $c_{6} ; \mathrm{C}_{550}$, the extrinsic cytochrome $c_{550}$ subunit of PSII; Fld, flavodoxin; Pc, E85K plastocyanin; PsaB, the membrane intrinsic subunit of PSI. Protein extracts: $30 \mu \mathrm{g}$ for Pc; $20 \mu \mathrm{g}$ for PsaB; $10 \mu \mathrm{g}$ for $\mathrm{C}_{6} ; 5 \mu \mathrm{g}$ for Fld; $2.5 \mu \mathrm{g}$ for $\mathrm{C}_{550}$. Membranes were incubated overnight with the following dilutions of the selected primary antibody: 1:500 anti-Pc; 1:1000 anti- $\mathrm{C}_{6}, \mathrm{CC}_{550}$ and PsaB; 1:50000 anti-Fld. (B) Spectroscopic monitoring of holo-Pc (ferricyanide minus ascorbate) in cell extracts from mutant \#45 under iron-deficient conditions. (C) Examples of WT and mutant \#45 individual cultures under iron-replete $(+)$ or irondeficient (-) conditions 

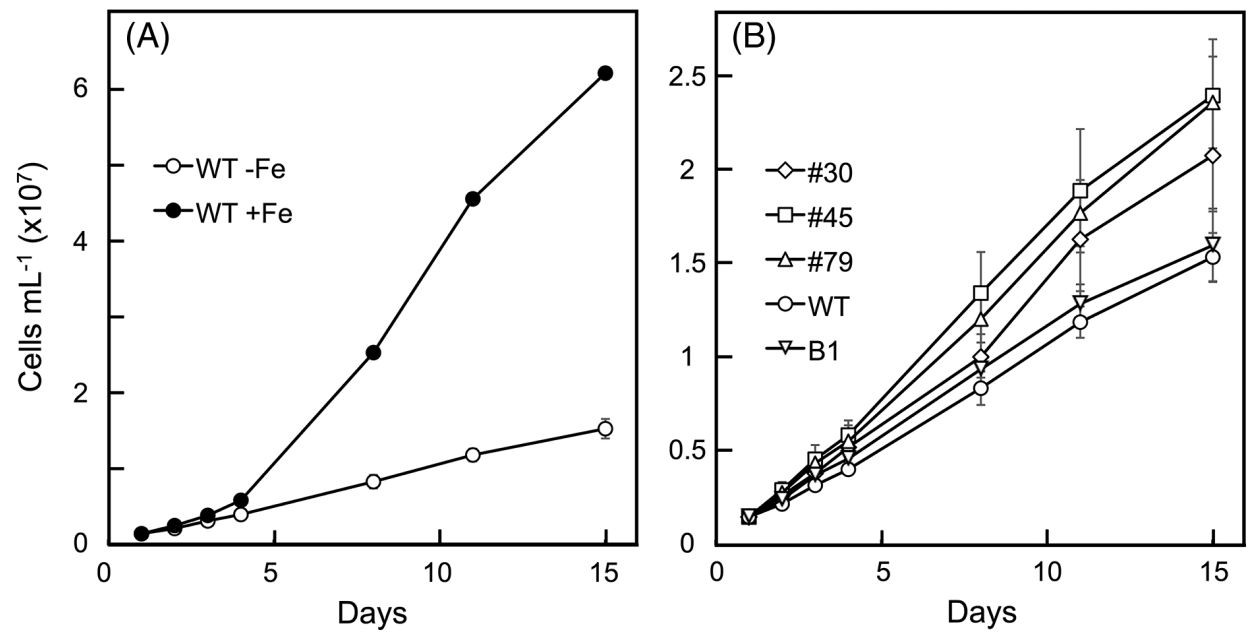

FIGURE 2 (A) Growth of $P$. tricornutum WT cultures under iron-replete $(+\mathrm{Fe})$ or iron-deficient (Fe) conditions. (B) Growth of WT, \#30, \#45, and \#79 strains cultures under iron-deficient conditions. Mean values \pm SD of measurements from 10 independent cultures are presented and \#79), as shown by the presence in western-blot analysis of a band corresponding to the expected size of $\mathrm{Pc}(10.2 \mathrm{kDa}$; Figure $1 \mathrm{~A})$. The following apparent progression in the levels of expression was observed: \#30 < \#45 < \#79 (Figure 1A). Whereas mutants \#30 and \#45 were transformed with the construction that contained the intron in the plastid targeting gene sequence, mutant \#79 lacked the intron (Figure S1), indicating that both constructions can be correctly processed. However, in the three mutant strains an additional band of an apparent higher size (12.6 kDa) was also observed (more abundant in the clone \#79; Figure $1 \mathrm{~A}$ ). This band can be tentatively assigned to unprocessed $\mathrm{Pc}$ molecules still containing the $\mathrm{Cc}_{6}$ thylakoid transit peptide (24 extra amino acids; Killian \& Kroth, 2004) and that would be considered as apo-Pc. Fluorescence microscopy monitoring of immunolabeled cells confirmed the detection of the heterologous Pc in the chloroplast, as the green fluorescence associated to the immunodetection of Pc merged with the red fluorescence of photosynthetic pigments (not shown). Finally, the presence of the Pc holoprotein (i.e., with the copper active cofactor) was directly detected by its absorption spectrum in cell extracts (Figure 1B). From the recorded differential spectra, analogous amounts of intracellular holo-Pc were estimated for mutants \#45 $(\approx 3.8 \mu \mathrm{M})$ and \#79 $(\approx 4.4 \mu \mathrm{M})$ (Figure 1B), whereas the lower levels of Pc detected in the mutant \#30 did not allow obtaining a reliable estimate of the holoprotein content. On the other hand, a similar amount of $\approx 3.6 \mu \mathrm{M}$ of intracellular $\mathrm{Cc}_{6}$ was estimated for the WT and mutant strains under iron-deficient conditions according to specific spectral changes (Figure S2), which represents $\approx 12 \%$ of the concentration detected under iron-replete conditions $(\approx 30 \mu \mathrm{M})$ (Bernal-Bayard et al., 2013).

\section{2 | Relatively low intracellular concentrations of heterologous $\mathrm{Pc}$ are enough to promote an increased growth in $P$. tricornutum under iron-deficient conditions}

It should be noted that, under iron-replete conditions, the transformed strains did not show significant differences with the WT strain (not shown), nor did the B1 strain (with the resistance to zeocin but without Pc) in iron-deficient conditions (Figure 2B). However, the three selected transformed strains showed an increased cell growth under iron-deficient conditions compared with the WT (and B1) strain (Figures $1 \mathrm{C}$ and $2 \mathrm{~B}$ ). This increase was about $40 \%$ in the mutant \#30, but up to $60 \%$ in the case of the \#45 and \#79 mutants (Figure 2B and Table 1), although the growth of the three transformed strains was still sensibly lower as compared with iron-replete conditions (Figure 2). Accordingly, the three transformed strains also showed higher values in the specific growth rate $\left(\mu\right.$, from 0.155 day $^{-1}$ in the WT to $0.175-0.185 \mathrm{day}^{-1}$ in the mutants), as well as in the total chlorophyll, chlorophyll $a$ and $c$ and carotenoid estimated contents per $\mathrm{ml}$, as compared with WT cells under iron-deficient conditions (Table 1). Higher levels of pigments are still observed in the three mutants when chlorophyll content is normalized per cell, particularly in the mutants \#45 and \#79 (up to 40\%; Table 1). Regarding global photosynthetic activity, the three transformed strains presented a significant enhancement in the net photosynthetic oxygen evolution normalized per cell compared with the WT strain, with the highest values observed again for the \#45 and \#79 clones (Table 1).

Fluorescence microscopy analysis showed changes in cell morphology in the three mutant strains (Figure S3 and Table 1). Thus, under iron-deficient conditions, WT fusiform cells showed to be more elongated than in the mutant strains (aspect ratio of 6.52, 4.89, 4.25, and 5.15 for WT, \#30, \#45, and \#79 cells, respectively). Consequently, the mutant strains also appeared with an increased circularity, which actually resulted in an increased cell volume (Table 1 ) and chloroplasts with a thicker shape (Figure S3).

The changes in the levels of some photosynthetic proteins under low iron conditions were visualized by western-blot analysis. In addition of Fld (used as a control of iron deficiency), the studied proteins included soluble $\mathrm{C}_{6}$, PSII subunits (the intrinsic D1 subunit and the luminal extrinsic subunits cytochrome $\mathrm{C}_{550}$-or $\mathrm{C}_{550^{-}}$and $\mathrm{PsbO}$ ), as well as the intrinsic PsaB subunit of PSI. The deficiency of iron promotes a drastic decrease in the levels of the two luminal cytochromes, $\mathrm{CC}_{6}$ and $\mathrm{CC}_{550}$, more particularly in the case of $\mathrm{CC}_{6}$, as previously described at less drastic iron limitations (Bernal-Bayard et al., 2017; Roncel et al., 2016) (Figure 1A). Western bands quantification allowed estimating a similar value of $\approx 10 \%$ in the levels of $\mathrm{Cc}_{6}$ and $\approx 30 \%$ in 
TABLE 1 General physiological and biochemical parameters of $P$. tricornutum transformed cells and cultures under iron-deficient conditions

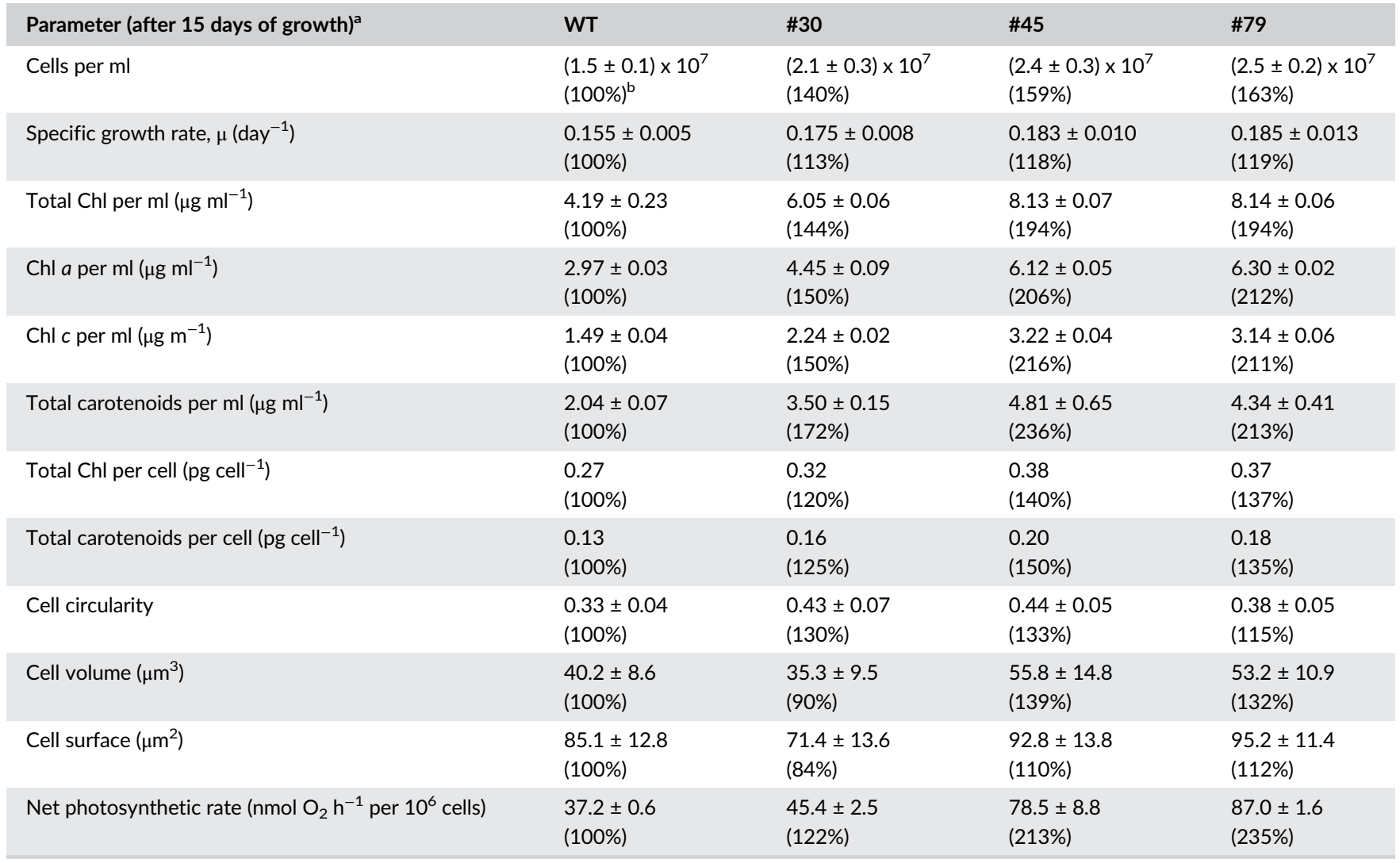

aSee the Materials and methods section for more details.

${ }^{b}$ Below, in parentheses, values referred to as the percentage of that of WT cells.

$\mathrm{C}_{550}$ in all the strains as compared with iron-replete conditions, in good agreement with the spectroscopic measurements (see above). Regarding other PSII components, the levels of PsbO and D1 were basically analogous in the WT and mutant strains under iron deficiency (Figure S4). However, in the case of the PsaB subunit of PSI, the decrease observed in the WT strain under iron-deficient conditions (to $\approx 40 \%$ of the iron-replete levels) seems to be somewhat recovered in the \#45 and more clearly in the \#79 mutant strains (Figure 1A). However, it is important to note that an increased level of PsaB does not necessarily imply an equivalent amount of active PSI, since other PSI iron-containing subunits are required to form functional PSI complexes (see below).

\subsection{P. tricornutum cells expressing Pc under low iron concentration show a lower decrease in PSII activity and a lower level of lipid peroxidation compared with WT cells}

The effects of iron deficiency on PSII ET activity of $P$. tricornutum WT and mutant strains were investigated using the STL technique (Figure 3). Excitation of iron-deficient $P$. tricornutum WT cells with two flashes at $1^{\circ} \mathrm{C}$ induced the appearance of a TL glow curve with significant differences in comparison with the curves obtained in ironreplete cells: a very significant decrease in the total TL signal intensity of about $65 \%$ (Figure 3A). The decomposition analysis of these emission curves allowed obtaining two components with similar $t_{\max }$ values of 14 and $28^{\circ} \mathrm{C}$ for both iron conditions. These two components can be assigned to the well-known $\mathrm{B} 1$ and $\mathrm{B} 2 \mathrm{TL}$ bands, originating from the recombination reactions of $\mathrm{S}_{3} \mathrm{Q}_{\mathrm{B}}{ }^{-}$and $\mathrm{S}_{2} \mathrm{Q}_{\mathrm{B}}{ }^{-}$charge pairs in PSII, respectively (Rutherford et al., 1984).

The TL glow curves obtained for the \#79 (Figure 3A), \#30 and \#45 (not shown) mutant strains could be also decomposed in two TL components: B1 and B2 bands. The $t_{\max }$ values for these components were similar to WT in all strains and for the two iron conditions. The TL glow curves obtained in iron-deficient cells also showed a decrease in the total TL signal intensity with respect to iron-replete conditions (Figure 3). However, the comparison between conditions of iron sufficiency or limitation for each strain indicated a much lower decrease in intensity in the mutants compared with the WT strain: $39 \%, 56 \%$, and $18 \%$ for \#30, \#45, and \#79 mutant strains, respectively (Figure 3B).

The HTL technique was applied to detect lipid peroxidation in $P$. tricornutum WT and mutant cells, cultured in both iron-replete and iron-deficient conditions. Figure 4A shows that a broad HTL2 band with a maximum between $130-140^{\circ} \mathrm{C}$ was present in iron-deficient WT cells. This band was significantly lower in iron-replete cells. Thus, an important level of lipid peroxidation was observed in WT cells grown in iron-deficient conditions under the relatively low light intensity used. However, for the three mutant strains cultured under irondeficient conditions, the level of lipid peroxidation was significantly lower (Figure 4B). 

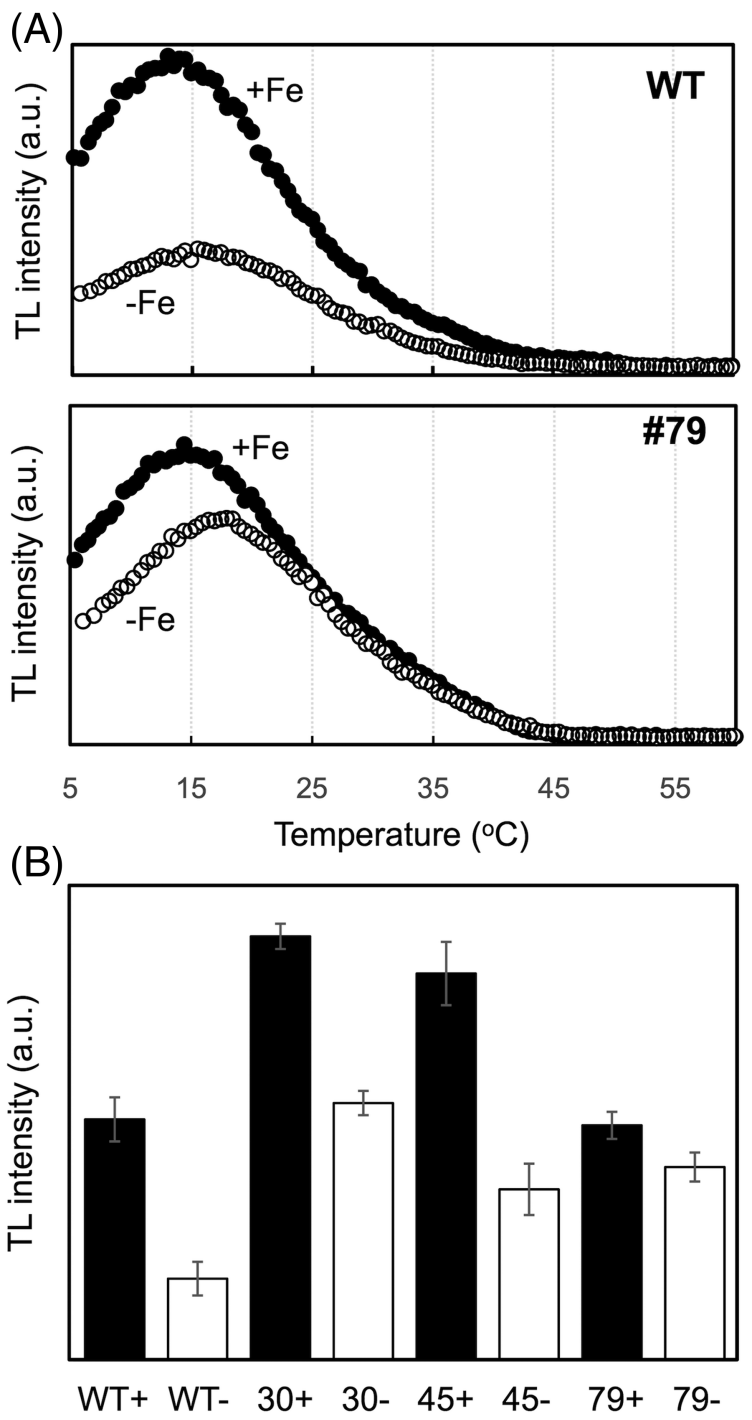

FIGURE 3 Effects of iron deficiency on the PSII activity of $P$. tricornutum cells measured by the STL technique.

(A) Representative standard TL glow curves of the WT and \#79 strains for iron-deficient (-Fe) and iron-replete (+Fe) conditions, as indicated. (B) Intensities of TL B1 and B2 bands for all the strains investigated under iron-replete (+) or iron-deficient (-) conditions, as indicated. Intensities were obtained from the component analysis of the curves of TL. Data in (B) represent mean values \pm SD of three independent measurements

\subsection{Higher maximum quantum yields of PSII and relative electron transport rates are observed by fluorescence measurements in P. tricornutum cells expressing Pc under iron-deficient conditions}

Differences in the photosynthetic activity of PSII between ironreplete and iron-deficient WT cells have been already described (Roncel et al., 2016). Thus, the effects of iron deficiency on PSII photochemistry in the mutants expressing Pc have been here investigated by chlorophyll $a$ fluorescence measurements. The maximum quantum yield of PSII, $F_{\mathrm{v}} / F_{\mathrm{m}}$, was significantly decreased in iron-deficient WT cells $\left(F_{\mathrm{v}} / F_{\mathrm{m}}=0.331\right)$ in comparison with iron-replete cultures $\left(F_{\mathrm{v}} /\right.$
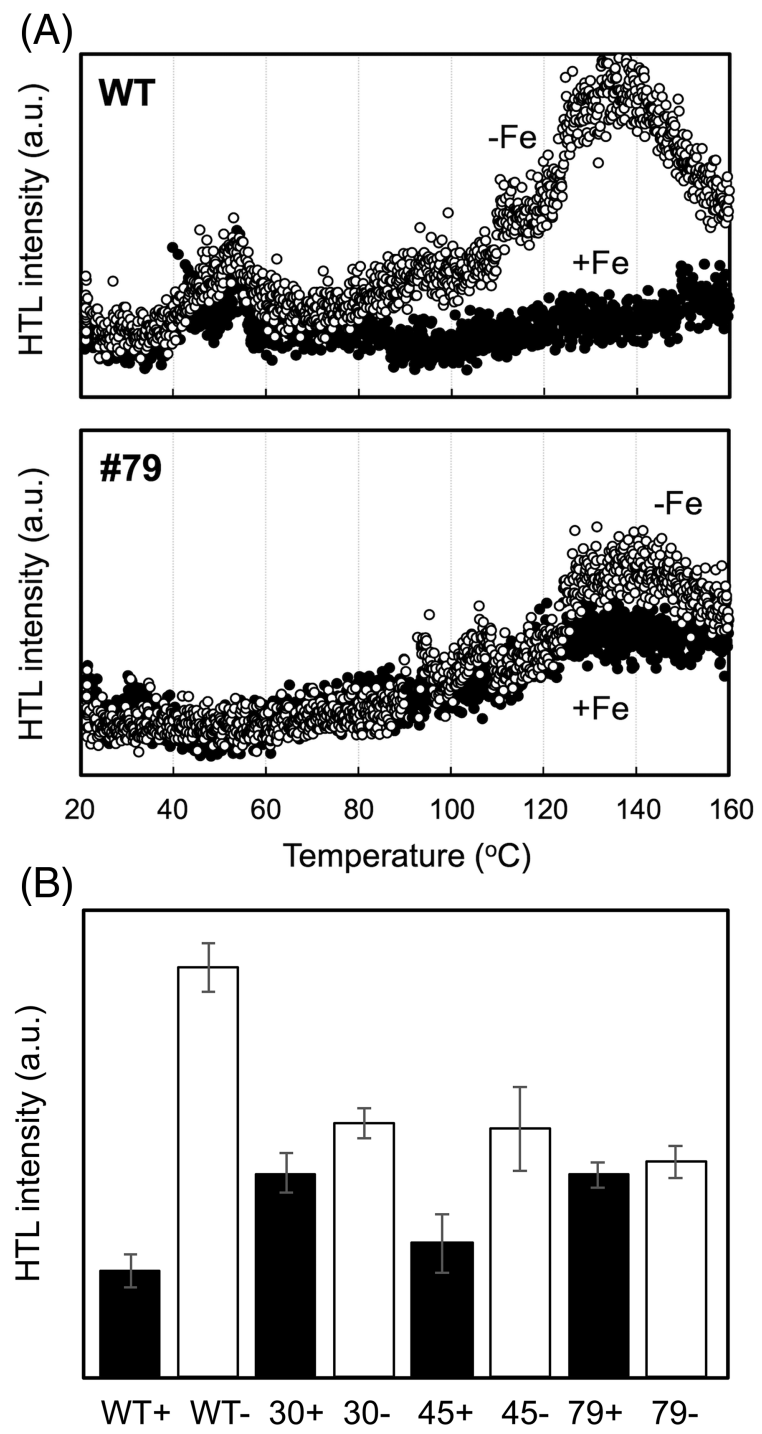

FIGURE 4 Effects of iron deficiency on the lipid peroxidation of $P$. tricornutum WT and mutant strains measured by the HTL technique. (A) Representative high-temperature TL glow curves (HTL2 band) of WT and \#79 mutant strains for iron-replete (+Fe) or irondeficient (-Fe) conditions, as indicated. (B) Intensities of HTL2 bands for all the strains investigated under iron-replete $(+)$ or iron-deficient $(-)$ conditions, as indicated. Intensities were obtained from the component analysis of the curves of HTL. Data in (B) represent mean values \pm SD of three independent measurements

$F_{m}=0.632$ ) (Table 2). However, the three mutants showed a partial recovery $(\approx 15-30 \%)$ of the $F_{\mathrm{v}} / F_{\mathrm{m}}$ values as compared to WT cells under conditions of iron deficiency, with higher values being obtained for the \#45 (0.384) and \#79 mutants (0.425) (Table 2).

It has been previously shown in cultures of $P$. tricornutum (Roncel et al., 2016) that the effective quantum yield of PSII, Y(II), is significantly lower in iron-deficient cultures as compared with ironreplete conditions at the range of irradiances used; iron-deficient cells being more sensitive to photoinhibition (Roncel et al., 2016). In our case, PSII light saturation curves carried out under iron deficiency have shown Y(II) values of a similar magnitude for the mutant strains compared to WT cells, although slightly higher values were 
TA B LE 2 Maximum quantum yield of PSII $\left(F_{v} / F_{m}\right)$, photosynthetically active radiation intensity (PAR) for relative maximum electron transport rate $\left(r E T R_{\max }\right)$, relative electron transport rate $(r E T R)$ at the maximum photosynthetically active radiation intensity $\left(P R_{\text {max }}\right)$, maximal $P_{700}{ }^{+}$signal upon full oxidation $\left(P_{\mathrm{m}}\right)$, and half-life time $\left(t_{1 / 2}\right)$ of the $\mathrm{P}_{700}{ }^{+}$re-reduction in iron-replete (+Fe) WT and iron-deficient $(-\mathrm{Fe})$ WT cells and the \#30, \#45, and \#79 mutants

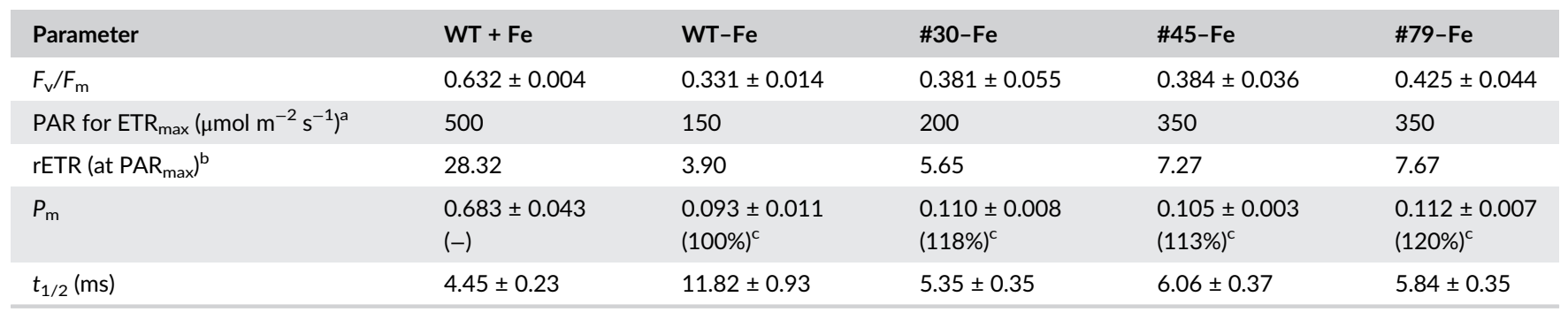

a Light intensity for $r E T R_{\max }$.

${ }^{b_{r E T R} \text { values at } 1292 \mu \mathrm{mol} \mathrm{m}}{ }^{-2} \mathrm{~s}^{-1}$ light intensity.

'Values as percentage of that of WT-Fe cells.

observed in the mutants at lower light intensities (Figure S5). On the other hand, it has also been shown that $P$. tricornutum cells showed differences in the relative electron transport rate (rETR, i.e., the ratio between absorbed light quanta and transported electrons) under iron-replete and iron-deficient conditions (Roncel et al., 2016). In cells exposed to gradually increasing light intensities, the electron transport increases in parallel up to its limit capacity. Beyond this point, increasing light intensity induces photoinhibition, that is, a decrease of the rETR (Bailleul et al., 2015; Roncel et al., 2016). In this work, iron-deficient WT cells reached its maximum electron transport rate $\left(\mathrm{rETR}_{\max }\right)$ at $150 \mu \mathrm{mol} \mathrm{m}{ }^{-2} \mathrm{~s}^{-1}$, showing inhibited rETR values at higher light intensities (about $30 \%$ of the maximum value at $\approx 1300 \mu \mathrm{mol} \mathrm{m} \mathrm{m}^{-2} \mathrm{~s}^{-1}$; Figure 5 and Table 2). In contrast, iron-replete WT cells have showed a rETR $\mathrm{rmax}_{\text {at }}$ $500 \mu \mathrm{mol} \mathrm{m}{ }^{-2} \mathrm{~s}^{-1}$ (Table 2) and, under these conditions, the rETR value measured at the higher light intensity remained at about $85 \%$ of the maximum value (not shown). Therefore, these results confirmed a substantially higher sensitivity to light for $P$. tricornutum WT cells grown under low iron concentration (Roncel et al., 2016). Table 2 shows the higher values of photosynthetically active radia-

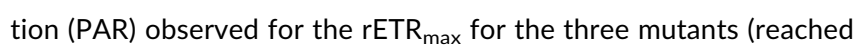
at $200-350 \mu \mathrm{mol} \mathrm{m}{ }^{-2} \mathrm{~s}^{-1}$ ), as compared to that obtained in the WT $\left(150 \mu \mathrm{mol} \mathrm{m}{ }^{-2} \mathrm{~s}^{-1}\right)$ under the same conditions. In addition, the three mutants showed higher $\mathrm{rETR}$ values at light intensities above $500 \mu \mathrm{mol} \mathrm{m} \mathrm{m}^{-2} \mathrm{~s}^{-1}$ and up to $\approx 1300 \mu \mathrm{mol} \mathrm{m}{ }^{-2} \mathrm{~s}^{-1}$, at which the rETR values still remained at about $50-65 \%$ of the maximum value. Higher values were again observed for the \#45 and \#79 mutants (Figure 5 and Table 2). The rETR values reported here under irondeficient conditions are similar to those previously described in P. tricornutum under a less severe iron-limitation (Roncel et al., 2016) and respiratory inhibition (Bailleul et al., 2015), but lower than those obtained in different culture and experimental conditions in response to $\mathrm{CO}_{2}$ limitation (Shimakawa et al., 2017). In any case, our results suggest that under iron deficiency, the three mutant strains exhibit better light tolerance, confirming the specific effect of expressing Pc in preventing earlier photoinhibition. This is also in line with the observed faster growth rate of the three mutants.

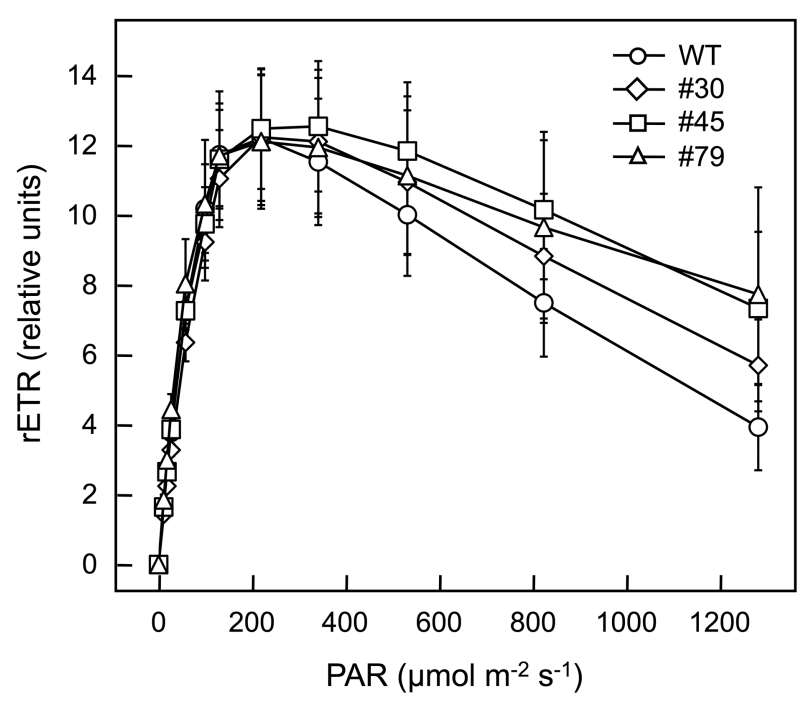

FIGURE 5 Relative linear electron transport rate (rETR) in the WT and \#30, \#45, and \#79 mutant strains of $P$. tricornutum cells under iron deficiency, as indicated. rETR values were determined as a function of irradiance derived from steady-state light curves. Chlorophyll fluorescence was measured with a pulse-amplitude modulation fluorometer and rETR values were determined during stepwise increasing photosynthetically active radiation (PAR) from 0 up to $1292 \mu \mathrm{mol} \mathrm{m}{ }^{-2} \mathrm{~s}^{-1}$ light intensity. Data represent mean values \pm SD of five independent measurements

\subsection{The heterologous expression of Pc in $P$. tricornutum promotes an increase in the maximum quantum yield of $\mathrm{PSI}$ and faster $\mathrm{P}_{700}$ reduction kinetics}

The effects of Pc expression on PSI activity under iron deficiency were also investigated by measuring the $P_{700}$ redox state changes during illumination, as previously described (Roncel et al., 2016). In dark-adapted cultures, $\mathrm{P}_{700}$ is reduced since the acceptor side of $\mathrm{P}_{700}$, that is, the Calvin-Benson cycle and subsequent reactions, is deactivated. Under actinic light, $\mathrm{P}_{700}$ is first oxidized and re-reduced by electrons coming from the plastoquinone (PQ) pool; thus, by applying saturating pulses, its ability to become oxidized and re-reduced can be determined (Roncel et al., 2016). Induction-recovery curves 


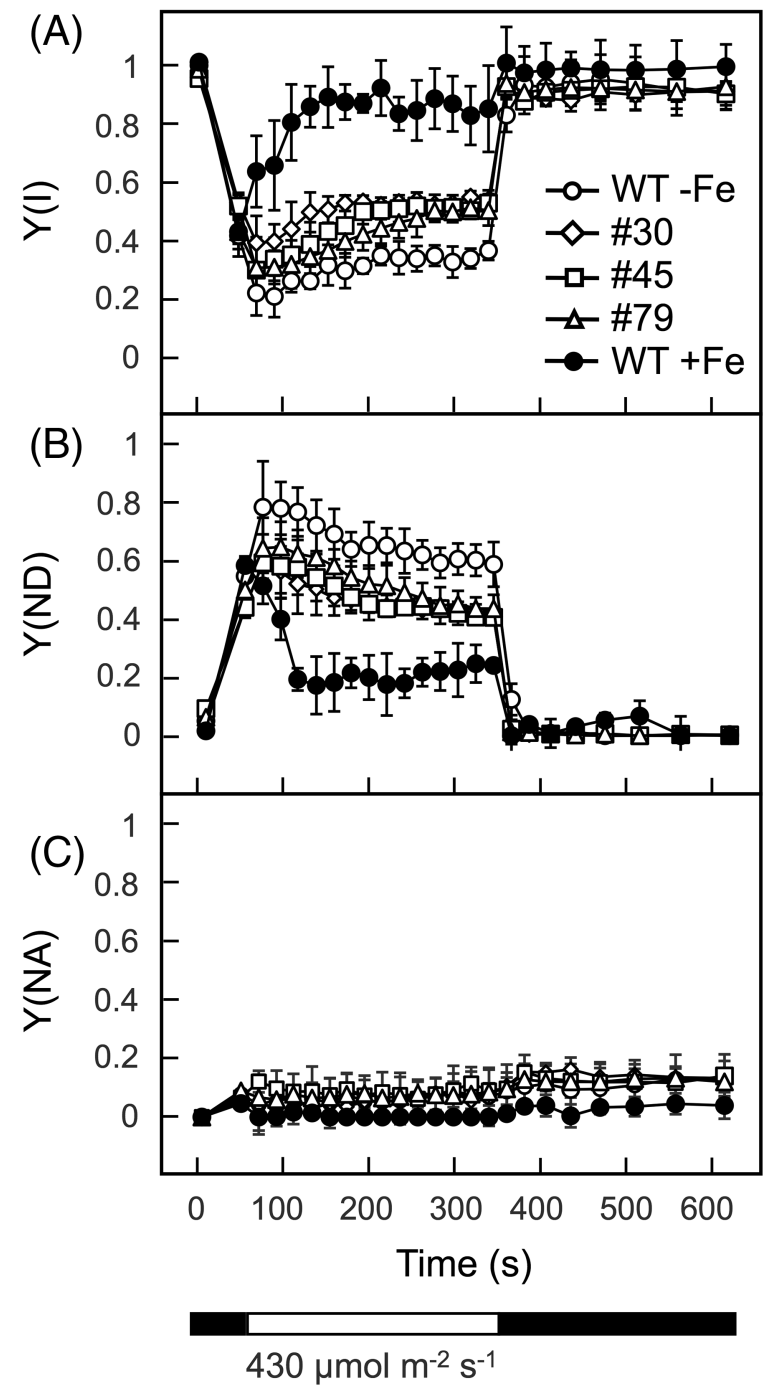

FIGURE 6 (A-C) PSI activity of WT (WT -Fe) and \#30, \#45, and \#79 mutant cells of $P$. tricornutum under iron deficiency. Values of WT cells in iron-replete conditions (WT +Fe) are also included as a control. The redox state of the PSI reaction center, $\mathrm{P}_{700}$, was monitored through the changes in absorbance at $830 \mathrm{~nm}$ versus $875 \mathrm{~nm}$, measured with a pulse-amplitude modulation fluorometer. Cultures of the different strains were kept in the dark for 30 min prior to the measurements. After the initial determination of the maximal oxidation of $\mathrm{P}_{700}$, actinic light was turned on at an intensity of $430 \mu \mathrm{mol} \mathrm{m} \mathrm{m}^{-2} \mathrm{~s}^{-1}$ and saturating pulses were applied every $20 \mathrm{~s}$. after 5 min, the actinic light was switched off and measurements continued for another $5 \mathrm{~min}$. Changes of (A) quantum yields of PSI, $Y(I)$, (B) donor side limitations, $Y(N D)$, and (C) acceptor side limitations, $\mathrm{Y}(\mathrm{NA})$, during the course of the induction curve are displayed. Data represent the mean values \pm SD of five independent measurements. White and black bars below graphs indicate periods of illumination with actinic light and darkness, respectively

were performed in iron-replete and iron-deficient cultures showing that the calculated quantum yield of PSI photochemistry $(\mathrm{Y}(\mathrm{I})$; Figure $6 \mathrm{~A}$ ) increased in the three mutants compared to WT cells under the same conditions of iron deficiency. On the other hand, the high degree of donor side limitations, Y(ND), observed in iron-deficient WT cells, was slightly reversed in all the mutants (Figure 6B).
The higher $Y(I)$ of the three mutants seems to indicate a recovery of the PSI activity missing in the WT cells as a result of the lack of availability of electron donors for PSI (Roncel et al., 2016). In contrast, similar acceptor-side limitations, $\mathrm{Y}(\mathrm{NA})$, were observed in all the cultures (Figure 6C). Thus, the presence of $\mathrm{Pc}$ in the three mutants seems to compensate for the deficiency in PSI activity by providing electrons to $\mathrm{PSI}$ in the light. To confirm this hypothesis, $\mathrm{P}_{700}$ reduction kinetics after saturating light pulses were recorded to obtain the maximal $\mathrm{P}_{700}{ }^{+}$signal upon full oxidation $\left(P_{\mathrm{m}}\right)$ and the half-life time $\left(t_{1 / 2}\right)$ parameters for $\mathrm{P}_{700}{ }^{+}$re-reduction (Table 2). After illumination with FR light and thereafter with a saturating light pulse, $\mathrm{P}_{700}$ became oxidized and reached a maximal level of $\mathrm{P}_{700}{ }^{+}$(Figure S6). As expected, the $P_{\mathrm{m}}$ signal amplitude was significantly lower in WT iron-deficient cells than in iron-replete conditions (Table 2). However, under conditions of iron deficiency, the three mutants exhibited a slightly higher $P_{m}$ signal compared to WT cells, thus indicating a somewhat higher amount of active $\mathrm{P}_{700}$ (Table 2). Following $P_{\mathrm{m}}$ determinations, $\mathrm{P}_{700}{ }^{+}$reduction kinetic decays were recorded in darkness and $t_{1 / 2}$ for the $\mathrm{P}_{700}{ }^{+}$ absorption decay could be calculated (Figure S6 and Table 2). Thus, the value of $t_{1 / 2}$ in WT iron-deficient cultures was $\approx 3$ times higher compared with iron-replete conditions (11.82 versus $4.45 \mathrm{~ms}$; Table 2). However, under iron deficiency, $t_{1 / 2}$ values were $\approx 2$ times lower in the three mutants $(\approx 5.8 \mathrm{~ms})$ in comparison with WT cells (Table 2), thus indicating an acceleration of $\mathrm{P}_{700}{ }^{+}$re-reduction in the three mutants as compared with iron-deficient WT cells (Table 2).

\section{DISCUSSION}

Adaptations of diatoms to natural oceanic low-iron environments include, among other effects, the induction of iron-uptake systems and the lowering of iron-containing photosynthetic proteins. In particular, a decrease in the levels of Fd (replaced by Fld) and the PSI and $\mathrm{Cb}_{6} \mathrm{f}$ complexes has been reported, thus decreasing iron requirements (Lommer et al., 2012; Strzepek \& Harrison, 2004). In addition, the presence of petE Pc genes in the genomes of some oceanic diatoms has been explained by their acquisition from green alga by horizontal gene transfer, as an adaptation to chronic iron limitations in these environments (iron concentration < $1 \mathrm{nM}$ ) (Moore \& Braucher, 2008). Thus, Pc acquisition and expression in oceanic diatoms has been considered to represent an alternative (or even constitutive) substitution of $\mathrm{Cc}_{6}$, as it occurs in cyanobacteria and green algae (Groussman et al., 2015; Hippmann et al., 2017; Lommer et al., 2012; Marchetti et al., 2012; Moore \& Braucher, 2008; Peers \& Price, 2006). An open question is the mechanism regulating a putative $\mathrm{Cc}_{6} / \mathrm{Pc}$ replacement in diatoms. In cyanobacteria and green algae, the copper levels determine the expression of one protein or another (Kropat et al., 2005; Merchant \& Bogorad, 1986; Sandmann, 1986). In diatoms, however, both low copper and sufficient iron conditions have been reported to induce a decrease in Pc transcripts which, on the contrary, can be detected under iron-limiting conditions (Hippmann et al., 2017; Lommer et al., 2012; Marchetti et al., 2012; Rizkallah et al., 2020). Recently, a threefold decrease in the Pc protein content under copper deficiency has been reported in T. oceanica (Kong \& Price, 2020). This 
is in contrast to the drastic changes in Pc content in response to changes in copper concentration observed in cyanobacteria and green algae (Durán et al., 2005; Merchant \& Bogorad, 1986; Sandmann, 1986). By its turn, our results indicate that $\mathrm{C}_{6}$ levels in P. tricornutum depend on the availability of iron (Roncel et al., 2016), although iron uptake itself is connected to copper availability (Maldonado et al., 2006).

Although a Pc holoprotein was purified from T. oceanica (Peers \& Price, 2006), this protein has neither been fully characterized nor cloned and expressed in Escherichia coli. Therefore, there are no functional data available for the interaction of the "red" partners (PSI or Cf) with the "green-type" Pc acquired by horizontal gene transfer. However, in vitro kinetic analysis of the interaction of $P$. tricornutum PSI with green algae and plants Pc indicated that diatom PSI is able to react with the very acidic $P c$ from these organisms, although with lower efficiency than with $P$. tricornutum $\mathrm{Cc}_{6}$. Moreover, in the C. reinhardtii E85K Pc mutant designed to mimic the electrostatics of diatom $\mathrm{Cc}_{6}$, this efficiency doubled as compared with the WT protein (Bernal-Bayard et al., 2015).

The estimated holo-Pc concentration per cell in T. oceanica under copper-sufficient conditions $(\approx 3 \mu \mathrm{M})$ is about 10 times lower than that usually described for $\mathrm{CC}_{6}$ under iron-sufficient conditions, including reported values in the coastal $P$. tricornutum diatom $(\approx 28 \mu \mathrm{M})$ (Bernal-Bayard et al., 2013; Kong \& Price, 2020; Peers \& Price, 2006). However, Pc levels in $T$. oceanica are comparable to the $\mathrm{C}_{6}$ content found under iron-deficient conditions in $P$. tricornutum $(\approx 4-7 \mu \mathrm{M}$ ) (see above, and Roncel et al., 2016) and, interestingly, to the levels of heterologous holo-Pc here detected $(\approx 4 \mu \mathrm{M})$. In this sense, although copper uptake systems have been described in T. oceanica (Kong \& Price, 2019), the functional expression of Pc requires a specific copper-transporting system into the thylakoid that has not yet been found in red-type organisms. A copper-trafficking system could expect to include chaperones for copper traffic and, in particular, a Ptype ATPase transporter located in the thylakoid membrane, delivering copper to the lumen for incorporation into Pc (Blaby-Haas \& Merchant, 2012; Guo et al., 2010, 2015; Kong \& Price, 2019; Nouet et al., 2011). Thus, it is possible that, in the absence of specific mechanisms of copper import, the limitation in copper available in the lumen to be incorporated into Pc restrains the amount of a functional holoprotein to the levels described in T. oceanica and found in this work (Ho et al., 2003, Levy et al., 2008, Twining \& Baines, 2013). However, our results indicate that even the relatively low concentrations of holo-Pc detected are enough to promote an increased growth (up to $60 \%$ in the case of the \#45 and \#79 mutants) under irondeficient conditions as compared with the WT strain (Figure 2). This increased growth can be measured as higher cell density, content in pigments (chlorophylls and carotenoids), global photosynthetic rates per cell and even cell volume (Table 1). Moreover, although the apparent partially recovered levels of psaB-more evident in mutant \#79does not allow to directly inferring an equivalent increase of active PSI, a slightly higher PSI activity has been also observed in the mutants in PAM experiments. Previous studies have proposed that, in P. tricornutum, the iron-rich PSI is degraded in iron-deficient conditions, mobilizing this element for other metabolic activities as respiration (Allen et al., 2008). The presence of Pc should not modify the extent of PSI degradation, as it does not alter the cell metabolic demand for iron. Thus, the observed data suggest that the balance of PSI synthesis/degradation under iron-limiting conditions is perhaps affected not only by iron requirements, but also by limitations at the PSI donor side or the global redox stress status of the chloroplast. Finally, the Pc-expressing strains also show changes in cell morphology and chloroplasts with a thicker shape, which indeed reflects changes in the physiological and metabolic status of cells (Levy et al., 2008; Martin-Jézéquel \& Tesson, 2013).

In addition, PSII activity of $P$. tricornutum cells was affected by low iron concentration in a different manner in the WT and mutant strains. The decreased PSII activity in iron-deficient conditions detected by TL experiments (Figure 3) may be attributed to a reduced amount of functional PSII complexes in cells (Msilini et al., 2011). The partial blocking of ET between PSII and PSI in cells cultured under iron-deficient conditions can generate the over-reduction of the PQ pool. Under iron-deficient conditions, $\mathrm{P}_{700}$ cannot become reduced, possibly due to fewer available iron-containing ET proteins downstream of the $\mathrm{PQ}$ pool, such as the $\mathrm{Cb}_{6} \mathrm{f}$ complex or the $\mathrm{Cc}_{6}$ soluble donor (Allen et al., 2008; Bruce \& Malkin, 1991; Greene et al., 1992; Roncel et al., 2016). In particular, in P. tricornutum cells grown under low iron conditions, the $\mathrm{Cc}_{6}$ concentration is reduced to $\approx 10-12 \%$ of the protein present in iron-replete cells, thus presumably disfavoring the $P Q$ pool re-oxidation (Roncel et al., 2016). An over-reduction of the $\mathrm{PQ}$ pool may induce the appearance of the acceptor side photoinhibition process, which can decrease PSII activity. The existence of an alternative electron carrier in the mutant strains, the E85K Pc, could improve the ET to PSI, and partially eliminate the overreduction of the PQ pool and the concomitant lack of activity of PSII. This hypothesis can explain the significant lower decrease of the TL intensity signal in the WT strain (Figure 3), as well as the higher maximum quantum yield of PSII obtained by fluorescence measurements in the mutants compared to the WT (Table 2). Higher values for $\mathrm{rETR}_{\max }$ were also determined in the three mutants with respect to the WT (Figure 5, Table 2), which indicates that the aforementioned occurrence of the acceptor side photoinhibition process is delayed due to the presence of Pc.

In chloroplasts, the reducing site of PSI and the oxidizing side of PSII are the major generation sites of reactive oxygen species (Sgherri et al., 2018). However, recently it has been reported that superoxide can also be produced by $\mathrm{Cb}_{6} \mathrm{f}$ and at the acceptor side of PSII (Roach \& Krieger-Liszkay, 2014). On the other hand, the major source of singlet oxygen appears to be PSII (Krieger-Liszkay, 2005; Murata et al., 2007), the generation of this reactive oxygen species is enhanced as a consequence of the photoinhibition of the acceptor side in PSII. The formation of singlet oxygen can initiate the peroxidation of unsaturated lipids in membranes (Vavilin \& Ducruet, 1998). The level of lipid peroxidation in photosynthetic membranes can be measured by the HTL technique (Roncel et al., 2007). Several luminescence high-temperature bands (HTL bands) have been observed without prior illumination at temperatures above $60^{\circ} \mathrm{C}$ (Ducruet \& Vavilin, 1999; Roncel et al., 2007). A broad HTL band centered near $130^{\circ} \mathrm{C}$ (known as the HTL2 band) is generated because of the thermal 
radiative decomposition of lipid peroxides that, in turn, leads to the formation of carbonyl groups in a triplet state followed by migration of excitation energy toward chlorophylls (Ducruet \& Vavilin, 1999; Vavilin et al., 2002; Vavilin \& Ducruet, 1998). The amplitude of this band has been well correlated with the accumulation of malondialdehyde, an indicator of lipid peroxidation in standard chemical tests (Vavilin et al., 2002; Vavilin \& Ducruet, 1998).

Analysis of HTL2 bands of TL obtained in P. tricornutum cells (Figure 4) clearly showed a much higher level of lipid peroxidation in iron-deficient conditions in the WT strain. However, in the three mutant strains the level of peroxidation did not significantly increase under iron-restricted conditions. These results suggest a higher rate of generation of reactive singlet oxygen under iron-deficient conditions in the WT strain. As previously said, the low levels of $\mathrm{C}_{6}$ probably induce the over-reduction of the $\mathrm{PQ}$ pool and the concomitant acceptor side photoinhibition in PSII, and thus singlet oxygen production. The existence of $\mathrm{Pc}$ in the mutant strains under iron-deficient conditions could partially eliminate the over-reduction of the PQ pool and the concomitant generation of singlet oxygen, thus decreasing oxidative stress and lipid peroxidation.

On the other hand, PSI activity is more sensitive to iron-limitation than PSII activity (Pushnik \& Miller, 1989; Roncel et al., 2016). The significant decrease in the quantum yield of PSI, $Y(I)$, observed in irondeficient WT cells (Figure 6) can be ascribed to a deficiency of PSI donors, which causes that $\mathrm{P}_{700}$ cannot become reduced (Allen et al., 2008, Bruce \& Malkin, 1991, Greene et al., 1992, Roncel et al., 2016). An increase of $Y(I)$ and a lower degree of limitation on the donor side of PSI, $Y(N D)$, have been here observed in the three mutants (Figure 6A-B). The existence of $\mathrm{Pc}$ as an additional electron carrier in the mutant strains seems to improve ET to PSI and, consequently, to partially increase $Y(I)$ as well as to decrease the overreduction of the $\mathrm{PQ}$ pool and the concomitant donor-side limitation of PSI.

In summary, our results show that the presence of $\mathrm{Pc}$ as an additional electron carrier in P. tricornutum under iron-limiting conditions seems to decrease the over-reduction of the PQ pool. This consequently promotes an improvement in the maximum quantum yield of both PSII and PSI, together with a decrease in the acceptor side photoinhibition of PSII, oxidative stress and the peroxidation of lipids, and a lower degree of limitation on the donor side of PSI. As a result, the mutants expressing Pc in P. tricornutum exhibit an enhancement in cell growth under iron-limiting conditions compared to WT cells.

\section{ACKNOWLEDGMENTS}

This article is dedicated to the memory of Jean-Marc Ducruet, to whom the authors will always be grateful for his support in the installation of thermoluminescence technology at the IBVF in Seville. This work was partially supported by the Spanish Ministry of Economy, Industry and Competitiveness (BIO2015-64169-P) and the Andalusian Government (PAIDI BIO-022). These grants were partially financed by the EU FEDER Program. C. Castell is the recipient of a FPU Program fellowship (Spanish Ministry of Education, Culture and Sports). The authors thank Dr. A. Orea (Microscopy Service, IBVF) for her technical assistance, Dr. V. Mariscal (IBVF) by his help in the immunolabeling microscopy experiments, Dr J. Paz and Prof. C. Bowler (IBENS, Paris, France) for kindly providing with the Isip1::YFP and pPha-T1 plasmids and the group of Biotecnología de semillas (IRNAS, Sevilla, Spain) for the use of their Biolistic system.

\section{AUTHOR CONTRIBUTIONS}

José A. Navarro and Manuel Hervás conceived and designed the project. Carmen Castell and Pilar Bernal-Bayard carried out the molecular biology genetic work as well as cells transformation and selection. Carmen Castell, with the help of José A. Navarro and Manuel Hervás, carried out the physiological and biochemical characterization of the different strains here studied. Mercedes Roncel and Carmen Castell carried out PAM experiments and José M. Ortega and Carmen Castell the TL measurements. All the authors discussed the results and José A. Navarro wrote the manuscript with their collaboration. The manuscript was corrected, revised and approved by all authors.

\section{DATA AVAILABILITY STATEMENT}

The data that support the findings of this study are available from the corresponding author upon reasonable request

\section{ORCID}

Carmen Castell (D) https://orcid.org/0000-0002-0920-4718 Pilar Bernal-Bayard (iD https://orcid.org/0000-0003-0243-1827 José M. Ortega (iD https://orcid.org/0000-0002-7841-3687 Mercedes Roncel (D) https://orcid.org/0000-0001-8749-7432 Manuel Hervás (D) https://orcid.org/0000-0003-4523-8891 José A. Navarro (D) https://orcid.org/0000-0002-0536-6074

\section{REFERENCES}

Akazaki, H., Kawai, F., Hosokawa, M., Hama, T., Chida, H., Hirano, T., et al. (2009) Crystallization and structural analysis of cytochrome $c_{6}$ from the diatom Phaeodactylum tricornutum at $1.5 \AA$ resolution. Bioscience, Biotechnology, and Biochemistry, 73, 189-191.

Allen, A.E., Laroche, J., Maheswari, U., Lommer, M., Schauer, N., Lopez, P. J., et al. (2008) Whole-cell response of the pennate diatom Phaeodactylum tricornutum to iron starvation. Proceedings of the National Academy of Sciences of the United States, 105(30), 10438-10443.

Antoshvili, M., Caspy, I., Hippler, M. \& Nelson, N. (2019) Structure and function of photosystem I in Cyanidioschyzon merolae. Photosynthesis Research, 139, 499-508.

Apt, K.E., Grossman, A.R. \& Kroth-Pancic, P.G. (1996) Stable nuclear transformation of the diatom Phaeodactylum tricornutum. Molecular \& General Genetics, 252, 572-579.

Arnon, D.I. (1949) Copper enzymes in isolated chloroplasts. Plant Physiology, 24, 1-15.

Bailleul, B., Berne, N., Murik, O., Petroutsos, D., Prihoda, J., Tanaka, A., et al. (2015) Energetic coupling between plastids and mitochondria drives $\mathrm{CO}_{2}$ assimilation in diatoms. Nature, 524, 366-369.

Bendall, D.S. \& Howe, C.J. (2016) The interaction between cytochrome $f$ and plastocyanin or cytochrome $c_{6}$. In: Cramer, W.A. \& Kallas, T. (Eds.) Cytochrome complexes: evolution, structures, energy transduction, and signaling. Advances in photosynthesis and respiration, Vol. 41. Dordrecht: Springer Science + Business Media, pp. 631-655.

Bernal-Bayard, P., Molina-Heredia, F.P., Hervás, M. \& Navarro, J.A. (2013) Photosystem I reduction in diatoms: as complex as the green lineage systems but less efficient. Biochemistry, 52, 8687-8695. 
Bernal-Bayard, P., Pallara, C., Castell, C., Molina-Heredia, F.P., FernándezRecio, J., Hervás, M., et al. (2015) Interaction of photosystem I from Phaeodactylum tricornutum with plastocyanins as compared with its native cytochrome $c_{6}$ : reunion with a lost donor. Biochimica et Biophysica Acta - Bioenergetics, 1847, 1549-1559.

Bernal-Bayard, P., Puerto-Galán, L., Yruela, I., García-Rubio, I., Castell, C., Ortega, J.M., et al. (2017) The photosynthetic cytochrome $c_{550}$ from the diatom Phaeodactylum tricornutum. Photosynthesis Research, 133, 273-287.

Blaby-Haas, C.E. \& Merchant, S.S. (2012) The ins and outs of algal metal transport. Biochimica et Biophysica Acta, 1823, 1531-1552.

Blankenship, R.E. (2014) Molecular mechanisms of photosynthesis, 2nd edition. Chichester, England: Wiley-Blackwell.

Bowler, C., Vardi, A. \& Allen, A.E. (2010) Oceanographic and biogeochemical insights from diatom genomes. Annual Review of Marine Science, 2, 333-365.

Boyd, P.W., Jickells, T., Law, C.S., Blain, S., Boyle, E.A., Buesseler, K.O., et al. (2007) Mesoscale iron enrichment experiments 1993-2005: synthesis and future directions. Science, 315, 612-617.

Bruce, B.D. \& Malkin, R. (1991) Biosynthesis of the chloroplast cytochrome $b_{6} f$ complex: studies in a photosynthetic mutant of Lemna. Plant Cell, 3, 203-212.

De la Rosa, M.A., Molina-Heredia, F.P., Hervás, M. \& Navarro, J.A. (2006) Convergent evolution of cytochrome $c_{6}$ and plastocyanin. The evolutionary pathways of the two proteins are connected to the geochemical changes in iron and copper availabilities. In: Golbeck, J.H. (Ed.) Photosystem I: the Ligth driven plastocyanin:ferredoxin oxidoreductase. Advances in photosynthesis and respiration, Vol. 24. Dordrecht: Springer, pp. 683-696.

Ducruet, J.M. \& Vavilin, D. (1999) Chlorophyll high-temperature thermoluminescence emission as an indicator of oxidative stress: perturbating effects of oxygen and leaf water content. Free Radical Research, 31 (Suppl), S187-S192.

Durán, R.V., Hervás, M., De la Rosa, M.A. \& Navarro, J.A. (2005) In vivo photosystem I reduction in thermophilic and mesophilic cyanobacteria: the thermal resistance of the process is limited by factors other than the unfolding of the partners. Biochemical and Biophysical Research Communications, 334, 170-175.

Falciatore, A., Casotti, R., Leblanc, C., Abrescia, C. \& Bowler, C. (1999) Transformation of nonselectable reporter genes in marine diatoms. Marine Biotechnology, 1(3), 239-251.

Falkowski, P.G., Katz, M.E., Knoll, A.H., Quigg, A., Raven, J.A., Schofield, O., et al. (2004) The evolution of modern eukaryotic phytoplankton. Science, 305(5682), 354-360.

Field, C.B., Behrenfeld, M.J., Randerson, J.T. \& Falkowski, P. (1998) Primary production of the biosphere: integrating terrestrial and oceanic components. Science, 281(5374), 237-240.

García-Calderón, M., Betti, M., Márquez, A.J., Ortega, J.M. \& Roncel, M. (2019) The afterglow thermoluminescence band as indicator of changes in the photorespiratory metabolism in the model legume Lotus japonicus. Physiologia Plantarum, 166, 240-250.

Goldman, J.C. \& McCarthy, J.J. (1978) Steady state growth and ammonium uptake of a fast-growing marine diatom. Limnology and Oceanography, 23(4), 695-703.

Greene, R.M., Geider, R.J., Kolber, Z. \& Falkowski, P.G. (1992) Iron-induced changes in light harvesting and photochemical energy conversion processes in eukaryotic marine algae. Plant Physiology, 100(2), 565-575.

Groussman, R.D., Parker, M.S. \& Armbrust, E.V. (2015) Diversity and evolutionary history of iron metabolism genes in diatoms. PLoS One, 10, e0129081.

Guo, J., Annett, A.L., Taylor, R.L., Lapi, S., Ruth, T.J. \& Maldonado, M.T. (2010) Copper-uptake kinetics of coastal and oceanic diatoms. Journal of Phycology, 46, 1218-1228.

Guo, J., Green, B.R. \& Maldonado, M.T. (2015) Sequence analysis and gene expression of potential components of copper transport and homeostasis in Thalassiosira pseudonana. Protist, 166, 58-77.
Guss, J.M. \& Freeman, H.C. (1983) Structure of oxidized poplar plastocyanin at $1.6 \AA$ A resolution. Journal of Molecular Biology, 169, 521-563.

Hall, D.O. (1976) Photobiological energy conversion. FEBS Letters, 64, 6-16.

Hanahan, D. (1983) Studies on transformation of Escherichia coli with plasmids. Journal of Molecular Biology, 166(4), 557-580.

Hervás, M., Navarro, J.A. \& De la Rosa, M.A. (2003) Electron transfer between soluble proteins and membrane complexes in photosynthesis. Accounts of Chemical Research, 36, 798-805.

Hervás, M., Navarro, J.A., Díaz, A., Bottin, H. \& De la Rosa, M.A. (1995) Laser-flash kinetic analysis of the fast electron transfer from plastocyanin and cytochrome $c_{6}$ to photosystem I. experimental evidence on the evolution of the reaction mechanism. Biochemistry, 34, 11321-11326.

Hippler, M. \& Drepper, F. (2006) Electron transfer between photosystem I and plastocyanin or cytochrome $c_{6}$. In: Golbeck, J.H. (Ed.) Photosystem I: the Ligth driven plastocyanin:ferredoxin oxidoreductase. Advances in photosynthesis and respiration, Vol. 24. Dordrecht: Springer, pp. 499-513.

Hippmann, A.A., Schuback, N., Moon, K.M., McCrow, J.P., Allen, A.E., Foster, L.J., et al. (2017) Contrasting effects of copper limitation on the photosynthetic apparatus in two strains of the open ocean diatom Thalassiosira oceanica. PLoS One, 12(8), e0181753.

Ho, T.Y., Quigg, A., Finkel, Z.V., Milligan, A.J., Wyman, K., Falkowski, P.G., et al. (2003) The elemental composition of some marine phytoplankton. Journal of Phycology, 39, 1145-1159.

Ish-Horowicz, D. \& Burke, J.F. (1981) Rapid and efficient cosmid cloning. Nucleic Acids Research, 9, 2989-2998.

Jeffrey, S. \& Humphrey, G. (1975) New spectrophotometric equations for determining chlorophylls $\mathrm{a}, \mathrm{b}, \mathrm{c} 1$ and $\mathrm{c} 2$ in higher plants, algae and natural phytoplankton. Biochemie und Physiologie der Pflanzen, 167, 191-194.

Kazamia, E., Sutak, R., Paz-Yepes, J., Dorrel, R.G., Vieira, F.R.J., Mach, J., et al. (2018) Endocytosis-mediated siderophore uptake as a strategy for Fe acquisition in diatoms. Science Advances, 4, 1-14.

Killian, O. \& Kroth, P.G. (2004) Presequence acquisition during secondary endocytobiosis and the possible role of introns. Journal of Molecular Evolution, 58, 712-721.

Kong, L. \& Price, N.M. (2019) Functional CTR-type Cu(I) transporters in an oceanic diatom. Environmental Microbiology, 21, 98-110.

Kong, L. \& Price, N.M. (2020) Identification of copper-regulated proteins in an oceanic diatom, Thalassiosira oceanica 1005. Metallomics, 12, 1106-1117.

Krieger-Liszkay, A. (2005) Singlet oxygen production in photosynthesis. Journal of Experimental Botany, 56, 337-346.

Kropat, J., Tottey, S., Birkenbihl, R.P., Depège, N., Huijser, P. \& Merchant, S. (2005) A regulator of nutritional copper signaling in Chlamydomonas is an SBP domain protein that recognizes the GTAC core of copper response element. Proceedings of the National Academy of Sciences of the United States, 102(51), 18730-18735.

Levy, J.L., Angel, B.M., Stauber, J.L., Poon, W.L., Simpson, S.L., Cheng, S.H., et al. (2008) Uptake and internalisation of copper by three marine microalgae: comparison of copper-sensitive and copper-tolerant species. Aquatic Toxicology, 89, 82-93.

Lommer, M., Specht, M., Roy, A.S., Kraemer, L., Andreson, R., Gutowska, M.A., et al. (2012) Genome and low-iron response of an oceanic diatom adapted to chronic iron limitation. Genome Biology, 13 (R66), 1-20.

Lowry, O.H., Rosebrough, N.J., Farr, A.L. \& Randall, R.J. (1951) Protein measurement with the folin phenol reagent. The Journal of Biological Chemistry, 193, 265-275.

Maldonado, M.T., Allen, A.E., Chong, J.S., Lin, K., Leus, D., Karpenko, N., et al. (2006) Copper dependent iron uptake in coastal and oceanic diatoms. Limnology and Oceanography, 51, 1729-1743.

Marchetti, A., Schruth, D.M., Durkin, C.A., Parker, M.S., Kodner, R.B., Berthiaume, C.T., et al. (2012) Comparative metatranscriptomics 
identifies molecular bases for the physiological responses of phytoplankton to varying iron availability. Proceedings of the National Academy of Sciences of the United States, 109, E317-E325.

Martin-Jézéquel, V. \& Tesson, B. (2013) Phaeodactylum tricornutum polymorphism: an overview. In: Heimann, K. \& Katsaros, C. (Eds.) Chapter 3Advances in algal cell biology. Berlin, Germany: De Gruyter publishing group, pp. 43-80.

McLachlan, J. (1964) Some considerations of the growth of marine algae in artificial media. Canadian Journal of Microbiology, 10(8104), 769-782.

Merchant, S. \& Bogorad, L. (1986) Regulation by copper of the expression of plastocyanin and cytochrome $c_{552}$ in Chlamydomonas reinhardi. Molecular and Cellular Biology, 6(2), 462-469.

Moore, J.K. \& Braucher, O. (2008) Sedimentary and mineral dust sources of dissolved iron to the world ocean. Biogeosciences, 5, 631-656.

Morrissey, J. \& Bowler, C. (2012) Iron utilization in marine cyanobacteria and eukaryotic algae. Frontiers in Microbiology, 3(43), 1-13.

Msilini, N., Zaghdoudi, M., Govindachary, S., Lachaâl, M., Ouerghi, Z. \& Carpentier, R. (2011) Inhibition of photosynthetic oxygen evolution and electron transfer from the quinone acceptor $\mathrm{Q}_{A}{ }^{-}$to $\mathrm{Q}_{B}$ by iron deficiency. Photosynthesis Research, 107(3), 247-256.

Murata, N., Takahashi, S., Nishiyama, Y. \& Allakhverdiev, S.I. (2007) Photoinhibition of photosystem II under environmental stress. Biochimica et Biophysica Acta, 1767, 414-421.

Nosenko, T., Lidie, K.L., Van Dolah, F.M., Lindquist, E., Cheng, J.F. \& Bhattacharya, D. (2006) Chimeric plastid proteome in the Florida "red tide" dinoflagellate Karenia brevis. Molecular Biology and Evolution, 23, 2026-2038.

Nouet, C., Motte, P. \& Hanikenne, M. (2011) Chloroplastic and mitochondrial metal homeostasis. Trends in Plant Science, 16, 395-404.

Peers, G. \& Price, N.M. (2006) Copper-containing plastocyanin used for electron transport by an oceanic diatom. Nature, 441, 341-344.

Pierella Karlusich, J.J., Lodeyro, A.F. \& Carrillo, N. (2014) The long goodbye: the rise and fall of flavodoxin during plant evolution. Journal of Experimental Botany, 65, 5161-5178.

Pushnik, J.C. \& Miller, G.W. (1989) Iron regulation of chloroplast photosynthetic function: mediation of PS I development. Journal of Plant Nutrition, 12(4), 407-421.

Rizkallah, M.R., Frickenhaus, S., Trimborn, S., Harms, L., Moustafa, A., Benes, V., et al. (2020) Deciphering patterns of adaptation and acclimation in the transcriptome of Phaeocystis Antarctica to changing iron conditions. Journal of Phycology, 56(3), 747-760.

Roach, T. \& Krieger-Liszkay, A. (2014) Regulation of photosynthetic electron transport and photoinhibition. Current Protein \& Peptide Science, 15, 351-362.

Rogl, H., Kosemund, K., Kühlbrandt, W. \& Collinson, I. (1998) Refolding of Escherichia coli produced membrane protein inclusion bodies immobilised by nickel chelating chromatography. FEBS Letters, 432, 21-26.

Roncel, M., González-Rodríguez, A.A., Naranjo, B., Bernal-Bayard, P., Lindahl, A.M., Hervás, M., et al. (2016) Iron deficiency induces a partial inhibition of the photosynthetic electron transport and a high sensitivity to light in the diatom Phaeodactylum tricornutum. Frontiers in Plant Science, 7(1050), 1-14.

Roncel, M., Yruela, I., Kirilovsky, D., Guerrero, F., Alfonso, M., Picorel, R., et al. (2007) Changes in photosynthetic electron transfer and state transitions in an herbicide-resistant D1 mutant from soybean cell cultures. Biochimica et Biophysica Acta, 1767(6), 694-702.

Rutherford, A.W., Renger, G., Koike, H. \& Inoue, Y. (1984) Thermoluminescence as a probe of photosystem II. The redox and protonation states of the secondary acceptor quinone and $\mathrm{O}_{2}$-evolving enzyme. Biochimica et Biophysica Acta, 767, 548-556.

Sambrook, J. \& Russell, D.W. (1989) Molecular cloning: a laboratory manual. New York: Cold Spring Harbor Laboratory Press.
Sancho, J. (2006) Flavodoxins: sequence, folding, binding, function and beyond. Cellular and Molecular Life Sciences, 63, 855-864.

Sandmann, G. (1986) Formation of plastocyanin and cytochrome $c_{553}$ in differents species of blue-green algae. Archives of Microbiology, 145, 76-79.

Schindelin, J., Arganda-Carreras, I., Frise, E., Kaynig, V., Longair, M., Pietzsch, T., et al. (2012) Fiji: an open-source platform for biologicalimage analysis. Nature Methods, 9(7), 676-682.

Sétif, P. (2006) Electron transfer from the bound iron-sulfur clusters to ferredoxin/flavodoxin: kinetic and structural properties of ferredoxin/flavodoxin reduction by photosystem I. In: Golbeck, J.H. (Ed.) Photosystem I: the Ligth driven Plastocyanin:ferredoxin oxidoreductase. Advances in photosynthesis and respiration, Vol. 24. Dordrecht: Springer, pp. 439-454.

Sgherri, C., Pinzino, C. \& Quartacci, M.F. (2018) Reactive oxygen especies and photosynthetic functioning: past and present. In: Singh, V.P., Singh, S., Tripathi, D.K., Prasad, S.M. \& Chauhan, D.K. (Eds.) Reactive oxygen species in plants: boon or bane-revisiting the role of ROS. Chichester, England: Chapter 7. John Wiley \& Sons Ltd, pp. 137-155.

Shimakawa, G., Matsuda, Y., Nakajima, K., Tamoi, M., Shigeoka, S. \& Miyake, C. (2017) Diverse strategies of $\mathrm{O}_{2}$ usage for preventing photo-oxidative damage under $\mathrm{CO}_{2}$ limitation during algal photosynthesis. Scientific Reports, 7, 41022.

Strickland, J.D.H. \& Parsons, T.R. (1972) A practical handbook of seawater analysis. Bulletin Fisheries Research Board of Canada, 167, 1-311.

Strzepek, R.F. \& Harrison, P.J. (2004) Photosynthetic architecture differs in coastal and oceanic diatoms. Nature, 431, 689-692.

Szabo, E. \& Colman, B. (2007) Isolation and characterization of carbonic anhydrases from the marine diatom Phaeodactylum tricornutum. Physiologia Plantarum, 129(3), 484-492.

Twining, B.S. \& Baines, S.B. (2013) The trace metal composition of marine phytoplankton. Annual Review of Marine Science, 5, 191-215.

Ubbink, M., Ejdebäck, M., Karlsson, B.G. \& Bendall, D.S. (1998) The structure of the complex of plastocyanin and cytochrome $f$, determined by paramagnetic NMR and restrained rigid-body molecular dynamics. Structure, 6, 323-335.

Vavilin, D.V. \& Ducruet, J.-M. (1998) The origin of $115-130{ }^{\circ} \mathrm{C}$ thermoluminescence bands in chlorophyll-containing material. Photochemistry and Photobiology, 68(2), 191-198.

Vavilin, D.V., Matorin, D.N. \& Rubin, A.B. (2002) High-temperature thermoluminescence of chlorophyll as a method to study lipid peroxidation in planktonic algae. Archiv für Hydrobiologie, 153(4), 685-701.

Yamada, S., Park, S.Y., Shimizu, H., Koshizuka, Y., Kadokura, K., Satoh, T., et al. (2000) Structure of cytochrome $c_{6}$ from the red alga Porphyra yezoensis at $1.57 \AA$ resolution. Acta Crystallographica. Section D, Biological Crystallography, 56, 1577-1582.

\section{SUPPORTING INFORMATION}

Additional supporting information may be found online in the Supporting Information section at the end of this article.

How to cite this article: Castell C, Bernal-Bayard P, Ortega JM, Roncel M, Hervás M, Navarro JA. The heterologous expression of a plastocyanin in the diatom Phaeodactylum tricornutum improves cell growth under irondeficient conditions. Physiologia Plantarum. 2021;171: 277-290. https://doi.org/10.1111/ppl.13290 